FEDERAL RESERVE BANK OF SAN FRANCISCO

WORKING PAPER SERIES

\title{
Decomposing the Fiscal Multiplier
}

\author{
James S. Cloyne \\ University of California, Davis \\ NBER and CEPR \\ Òscar Jordà
}

Federal Reserve Bank of San Francisco

University of California, Davis

Alan M. Taylor

University of California, Davis

NBER and CEPR

September 2020

Working Paper 2020-12

https://www.frbsf.org/economic-research/publications/working-papers/2020/12/

\section{Suggested citation:}

Cloyne, James S., Òscar Jordà, Alan M. Taylor. 2020. "Decomposing the Fiscal Multiplier," Federal Reserve Bank of San Francisco Working Paper 2020-12.

https://doi.org/10.24148/wp2020-12

The views in this paper are solely the responsibility of the authors and should not be interpreted as reflecting the views of the Federal Reserve Bank of San Francisco or the Board of Governors of the Federal Reserve System. 


\title{
Decomposing the Fiscal Multiplier ${ }^{\star}$
}

\author{
James S. Cloyne ${ }^{\dagger} \quad$ Òscar Jordà $\quad$ Alan M. Taylor $\S$
}

September 2020

\begin{abstract}
The fiscal "multiplier" measures how many additional dollars of output are gained or lost for each dollar of fiscal stimulus or contraction. In practice, the multiplier at any point in time depends on the monetary policy response and existing conditions in the economy. Using the IMF fiscal consolidations dataset for identification and a new decomposition-based approach, we show how to quantify the importance of these monetary-fiscal interactions. In the data, the fiscal multiplier varies considerably with monetary policy: it can be zero, or as large as 2 depending on the monetary offset. More generally, we show how to decompose the typical macro impulse response function by extending local projections to carry out the well-known Blinder-Oaxaca decomposition. This provides a convenient way to evaluate the effects of policy, state-dependence, and balance conditions for identification.

JEL classification codes: $\mathrm{C}_{54}, \mathrm{C}_{99}, \mathrm{E}_{32}, \mathrm{E} 62, \mathrm{H}_{20}, \mathrm{H}_{5}, \mathrm{~N} 10$.

Keywords: Fiscal multiplier, monetary offset, Blinder-Oaxaca decomposition, local projections, interest rates, fiscal policy, state-dependence, balance, identification.
\end{abstract}

${ }^{\star}$ We thank Helen Irvin and Chitra Marti for excellent research assistance. We are also grateful to Alan Auerbach, Olivier Blanchard, Roger Farmer, Emi Nakamura, Gernot Mueller and participants at the NBER Summer Institute 2020 and the Econometric Society World Congress 2020 for very helpful comments and suggestions. The views expressed in this paper are the sole responsibility of the authors and to not necessarily reflect the views of the Federal Reserve Bank of San Francisco or the Federal Reserve System.

${ }^{\dagger}$ Department of Economics, University of California, Davis; NBER; and CEPR (jcloyne@ucdavis.edu).

$\ddagger$ Federal Reserve Bank of San Francisco; and Department of Economics, University of California, Davis (oscar.jorda@sf.frb.org; ojorda@ucdavis.edu).

$\S$ Department of Economics and Graduate School of Management, University of California, Davis; NBER; and CEPR (amtaylor@ucdavis.edu). 


\section{INTRODUCTION}

What is the fiscal multiplier? In principle the definition is clear: The multiplier tells us how many extra dollars of additional economic output are gained or lost by changing government expenditure or taxation (or a mix of the two) by one dollar. Given the turbulent economic events of the last decade or so-and those now underway-there continues to be much interest in empirical estimates of this object. However, there is no such thing as the fiscal multiplier. One of the most obvious reasons is that monetary policy may not offset the effects of fiscal policy in the same way across states of the world, countries, or time.

This insight, of course, exists in many macroeconomic theories and has been noted in policy debate. The fiscal multiplier in the data is not necessarily, for example, the same object as the Keynesian multiplier found in many undergraduate textbooks. That concept, which follows from the Keynesian Cross, usually assumes unchanged interest rates. Recent theoretical work on the Zero Lower Bound (ZLB) on interest rates notes that when monetary policy is unable or unwilling to offset the effects of a fiscal stimulus, fiscal multipliers can be considerably larger. ${ }^{1}$ And, more generally, several papers using New Keynesian models note that the fiscal multiplier is sensitive to the degree of monetary accommodation, a theoretical result that is part of our main motivation. ${ }^{2}$ To date, however, there is relatively little evidence quantifying the importance of the "monetary offset" empirically. As a result, much policy advice has been given using multiplier estimates that are likely to depend on the particular average response of monetary policy in the past.

In this paper we introduce a new empirical approach for examining this interaction of monetary and fiscal policy. Our goal is to answer a question that has remained unresolved in the literature up to now: Does the fiscal multiplier in the data depend on the behavior of monetary policy? And, if so, by how much? In trying to answer these questions, we introduce a new way to deconstruct impulse responses. We first show that the local projection (LP) approach in Jordà (2005) can be easily extended to carry out the well-known Blinder-Oaxaca decomposition (Blinder, 1973; Oaxaca, 1973). This decomposition is standard in applied microeconomics (Fortin, Lemieux, and Firpo, 2011), but has not found equivalent acceptance in applied macroeconomics. We argue that it should.

The Blinder-Oaxaca decomposition of an impulse response function allows us to evaluate three separate effects following an exogenous change in fiscal policy: First, the direct effect of a fiscal intervention on outcomes, such as GDP. This effect embeds the typical response of monetary policy (and of other controls) in the sample. Second and most important for our purpose, the indirect effect. Policy interventions can themselves modify how other variables influence the outcomes. This motivates a very natural way to think about monetary-fiscal interactions: fiscal treatment may be less effective if there is a monetary offset. Third, the composition effect. This allows us to quantify, in an easily expressible manner, any bias due to imperfect identification. If fiscal interventions are

\footnotetext{
${ }^{1}$ See, e.g., Christiano, Eichenbaum, and Rebelo (2011); Eggertsson (2011)

${ }^{2}$ For example, see Woodford (2011) for an analysis of this point in the standard closed economy New Keynesian model and Leeper, Traum, and Walker (2017) in the context of a larger medium-scale DSGE model.
} 
truly exogenous, the average value of the controls should be the same whether or not there is an exogenous fiscal intervention. In small samples, this will not be exactly true even in the ideal case, let alone when identification fails.

State-dependent impulse response applications are numerous (as we will discuss in more detail momentarily). How is our analysis any different? What is gained from the Blinder-Oaxaca decomposition? We argue that one cannot understand when are state-dependent impulse responses correctly estimated without our conceptual framework. In particular, we highlight two features that have been largely neglected in the literature so far. First, one requires further identification assumptions to capture exogenous variation in the states themselves. Without it, state dependent impulse responses cannot be causally interpreted. Second, the states themselves depend, in principle, on the values of all other covariates in the conditional mean and not just the state variable. Thus, separate from the state variable, and in addition to it, conditions in the economy at the time of the intervention will determine the actual response experienced. Even if the state-dependent impulse response is correctly characterized, the actual response experienced will depend on prevailing factors at the time of intervention. Thus, our decomposition makes clear and measurable what are the sources of heterogeneity.

This paper therefore makes three main contributions. First, using our approach, we show that fiscal multipliers are around or below 1 on average, but there is a sizable degree of heterogeneity. Second, on the latter point, following a fiscal contraction, when the degree of monetary accommodation is limited, fiscal multipliers can become large. In our policy experiments, fiscal multipliers can be as low as zero, or as high as 2 depending on the monetary policy configuration. The latter is similar to the original multiplier of 2.5 posited by Keynes (1936). This result also has wider theoretical implications as an interaction effect is only present in models with nominal rigidities and where fiscal policy, at least partly, affects GDP through aggregate demand. Third, we show how to introduce decomposition methods in macroeconomics more generally. Our decomposition approach turns out to be straightforward to implement and allows for a great deal of unspecified heterogeneity. We show that a number of other state variables, such as the change in the fiscal deficit and the size of the fiscal consolidation, do not materially affect the size of the fiscal multiplier. However, like other papers in the literature, we confirm that fiscal multipliers are larger in slumps (cyclically-low output states). Our approach will hopefully have practical implications for all researchers interested in estimating the non-linear, state-dependent, or time-varying effects of policy interventions using straightforward linear estimators.

Although the new decomposition methods introduced here are an important refinement, in principle they have some important limitations. As Fortin, Lemieux, and Firpo (2011) have noted, the Blinder-Oaxaca decomposition itself follows a partial equilibrium type of approach. In particular, it is not necessarily correct to infer how much more or less effective a policy would be if, say, GDP growth were negative versus positive. The decomposition measures differences in fiscal policy effectiveness by averaging across alternative historical episodes whose make-up it takes as given. The chosen dimension of heterogeneity is, however, likely to be correlated with many other macroeconomic 
outcomes. This insight, which clearly follows from the Blinder-Oaxaca decomposition, illustrates the issue facing almost all papers in the existing state-dependence literature. Understanding the state dependent nature of policy interventions in a causal sense requires further identifying assumptions.

To take the next step and address this issue, we will use cross-country panel data and exploit the fact that different countries may have different monetary regimes with respect to accommodation. This heterogeneity makes interest rates differentially sensitive to fiscal policy on average and generates cross-sectional variation that is useful for identification. This differential sensitivity allows us to construct a proxy for the monetary regime that we can vary to undertake policy experiments. ${ }^{3}$ Using this feature of the data, we show that fiscal interventions have very different effects on GDP depending on whether the intervention occurs in a more or less accommodative monetary regime. 4 Exploiting the Blinder-Oaxaca decomposition, we can then quantify how the fiscal multiplier varies with the degree of monetary accommodation.

Naturally, this paper is related to a sizable literature on the empirical fiscal multiplier. For example, Blanchard and Perotti (2002) and Mountford and Uhlig (2009) identify the effect of fiscal policy by imposing restrictions in a vector autoregression (VAR) framework. Numerous applications have followed these VAR-based approaches. Romer and Romer (2010) pioneered a "narrative" approach which uses historical information to isolate episodes of exogenous fiscal policy changes unrelated to current economic conditions. These methods are essentially looking for historical natural experiments. A number of papers have applied or refined this method including Barro and Redlick (2011), Cloyne (2013), Mertens and Ravn (2013), Guajardo, Leigh, and Pescatori (2014), Hayo and Uhl (2014), Cloyne and Surico (2017), Gunter, Riera-Crichton, Végh, and Vuletin (2018), Nguyen, Onnis, and Rossi (2020), Hussain and Lin (2018), Cloyne, Dimsdale, and Postel-Vinay (2018).

Following the narrative tradition, we will use an influential and established study from the IMF which identifies periods of exogenous fiscal treatment. This study by Guajardo, Leigh, and Pescatori (2014) employs the Romer and Romer (2010) definition of an exogenous fiscal consolidation to identify exogenous episodes across 17 OECD countries from 1978 to 2009. There are a few key reasons for using the Guajardo, Leigh, and Pescatori (2014) dataset. First, our contribution is not a new identification of fiscal shocks. Rather, we take the existing Guajardo, Leigh, and Pescatori (2014) consolidation episodes off the shelf, and then show how the fiscal multiplier varies with monetary policy. Second, as noted above, the cross-country nature of the data allows us to exploit the panel nature of the dataset for identification of the monetary offset. Third, studying non-linear effects and state-dependence naturally asks more of the data and larger sample sizes are preferable.

In considering how the effect of a fiscal intervention varies with monetary policy, we also relate to a growing literature on the state-dependent effects of policy changes. For example, a number of papers have examined whether the impact of fiscal policy could vary depending on economic circumstances (Auerbach and Gorodnichenko, 2012; DeLong and Summers, 2012; Bachmann and

${ }^{3}$ We discuss the more detailed assumptions below.

4In exploiting the differential sensitivity of countries to shocks, our method has a connection to the approach in Nakamura and Steinsson (2014) and Guren, McKay, Nakamura, and Steinsson (2020). 
Sims, 2012; Riera-Crichton, Vegh, and Vuletin, 2015; Jordà and Taylor, 2016). This literature has often focused on a particular dimension of state dependence such as booms versus slumps, or expansions versus recessions. Another related literature has considered whether the fiscal multiplier is larger when there is no response of monetary policy at the Zero Lower Bound (e.g., Ramey and Zubairy, 2018; Crafts and Mills, 2013; Kato, Miyamoto, Nguyen, and Sergeyev, 2018; Miyamoto, Nguyen, and Sergeyev, 2018). Canova and Pappa (2011) use sign-restrictions in a vector auto-regression framework and find that imposing a no-monetary response generates a larger multiplier.

Our findings also relate to multiplier estimates using regional variation where, among other things, the aggregate effects of monetary policy are held constant (for examples see Acconcia, Corsetti, and Simonelli, 2014; Nakamura and Steinsson, 2014; Corbi, Papaioannou, and Surico, 2019). Reviewing this literature, Chodorow-Reich (2019) concludes that these "cross-sectional" multipliers are consistent with an aggregate "no-monetary-policy-response" multiplier of 1.7 or above. 5 Finally, some papers find that the exchange rate regime affects the size of the multiplier (e.g., Corsetti, Meier, Müller, and Devereux, 2012; Born, Juessen, and Müller, 2013; Ilzetzki, Mendoza, and Végh, 2013), which is obviously related to whether policymakers can use monetary tools.

These existing papers highlight the importance of the monetary offset, but often refer to a particular environment (e.g., the zero lower bound) and it is hard to know the right benchmark against which to measure the "usual" monetary response. Relative to all these papers, our focus is therefore different. We aim to directly quantify the importance of this monetary-fiscal interaction on the aggregate fiscal multiplier more generally, and not just in certain episodes, and thus map out a range for how the fiscal multiplier varies with the monetary offset.

The structure of the paper is as follows. Next, in Section 2, we discuss the data and outline the general empirical approach. Section 3 formally discusses the decomposition methods we use and how these can be introduced into macroeconomic analysis using local projections. Section 4 applies this new method to study the interaction of monetary policy and the fiscal multiplier. Section 5 illustrates the success of the Blinder-Oaxaca approach and our identification strategy using simulations from a New Keynesian model where the fiscal multiplier varies with the degree of monetary offset. Section 6 conducts a number of robustness checks. We then conclude and discuss some policy implications.

\section{Motivation AND DATA}

Our goal is to study the dynamic causal effect of changes in fiscal policy on economic activity, and to estimate how this effect might vary with monetary policy. As mentioned in the introduction our contribution is not about the identification of fiscal shocks. We therefore rely on an off-the-shelf and well-established dataset of exogenous fiscal interventions: Guajardo, Leigh, and Pescatori (2014)

\footnotetext{
5Guajardo, Leigh, and Pescatori (2011) also discuss how the degree of monetary accommodation might explain differences between their estimated spending and tax multipliers but do not formally attempt to estimate this interaction more generally.
} 
construct a cross-country panel dataset of plausibly exogenous movements in government spending and taxes that were introduced for the purpose of fiscal consolidation. The identification approaches follows Romer and Romer (2010) and focuses on consolidations that were designed to tackle an inherited historical budget deficit, but were not responding to current business cycle fluctuations.

Although Guajardo, Leigh, and Pescatori (2014) use a mix of distributed lag models and vector autoregressions for estimation, in the next section we will follow Jordà and Taylor (2016) and employ local projections to show how the Blinder-Oaxaca decomposition can be tractably applied to the estimation of impulse response functions in that framework. When we estimate these local projections our baseline specification is

$$
y_{i, t+h}-y_{i, t-1}=\mu_{i}^{h}+\left(x_{i, t}-\bar{x}_{i}\right) \gamma^{h}+f_{i, t} \beta^{h}+\omega_{i, t+h} \quad h=0,1, \ldots, H,
$$

where $y$ is a particular variable of interest, for example log GDP or the real interest rate; $t$ refers to the time period and $i$ refers to the country; $\mu_{i}$ is a country fixed effect; $x_{i, t}$ is a vector of additional controls, with mean $\bar{x}_{i}$; and $f_{i, t}$ is the policy intervention or treatment, in this case the country-specific fiscal consolidation shock. In typical empirical fiscal multiplier papers, $\beta^{h}$ is the key object of interest: the percent effect on, e.g., GDP, following a $1 \%$ of GDP fiscal consolidation. ${ }^{6}$ As additional controls we include two lags of the deficit to GDP ratio, the change in the real interest rate and, following Jordà and Taylor (2016), the output gap to control for the state of the cycle.7

In terms of the dependent variables, a number of variables of interest - such as the response of the deficit to GDP ratio - are not available in the Guajardo, Leigh, and Pescatori (2014) dataset. We therefore merge the Guajardo, Leigh, and Pescatori (2014) fiscal consolidation shocks with the Jordà, Schularick, and Taylor (2017) Macrohistory Database (http://www . macrohistory .net/ data/), which contains a wider array of variables that we can employ as outcomes in our local projection analysis.

As an empirical starting point, Figure 1 motivates our paper by showing the impulse response functions estimated from Equation 1 . The figure shows that a $1 \%$ of GDP improvement in the government fiscal balance leads to a peak fall in GDP of around $1 \%$ over 4 years. Despite some differences in sample and specification, Panel (a) of Figure 1 is very similar to the original results in Guajardo, Leigh, and Pescatori (2014). The comparable IRF is shown in Figure 2 of the working paper version, Guajardo, Leigh, and Pescatori (2011), and is very similar to Figure 1, with a peak effect on GDP occurring 2-3 years after the shock, and between 0.5 and $1 \%$ in magnitude. ${ }^{8}$

\footnotetext{
${ }^{6}$ This could be interpreted as one measure of a fiscal multiplier. But later we compute cumulative multipliers from the IRFs to explicitly take account of the full dynamic path of GDP and the fiscal variables.

7Including time fixed effects extends standard error bands without affecting the point estimates. Thus, to improve the precision of the estimates in the Blinder-Oaxaca decomposition discussed below, we capture a time-varying global factor by including world real GDP growth.

${ }^{8}$ Guajardo, Leigh, and Pescatori $(2011,2014)$ estimate the following type of empirical specification:

$$
\Delta y_{i, t}=a_{i}+\lambda_{t}+\sum_{j=1}^{2} b_{i} \Delta y_{i, t-j}+\sum_{j=0}^{2} c_{j} F_{i, t-j}+e_{i, t}
$$
}


Figure 1: Effects of a 1 percentage point of GDP fiscal consolidation

(a) Response of GDP (\%)

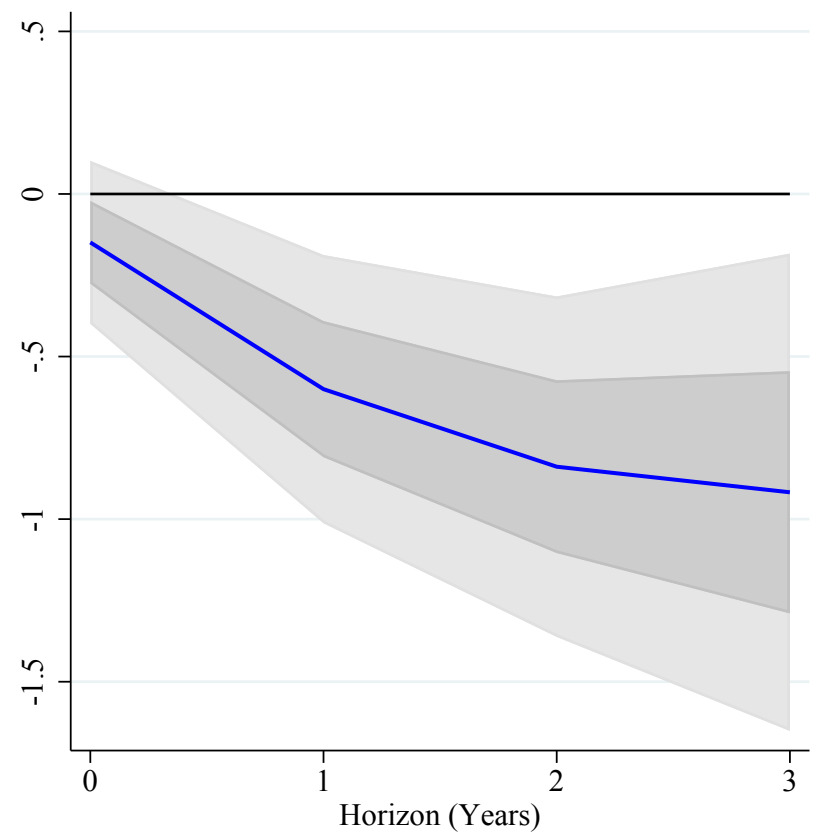

(b) Response of short term real interest rate (\% points)

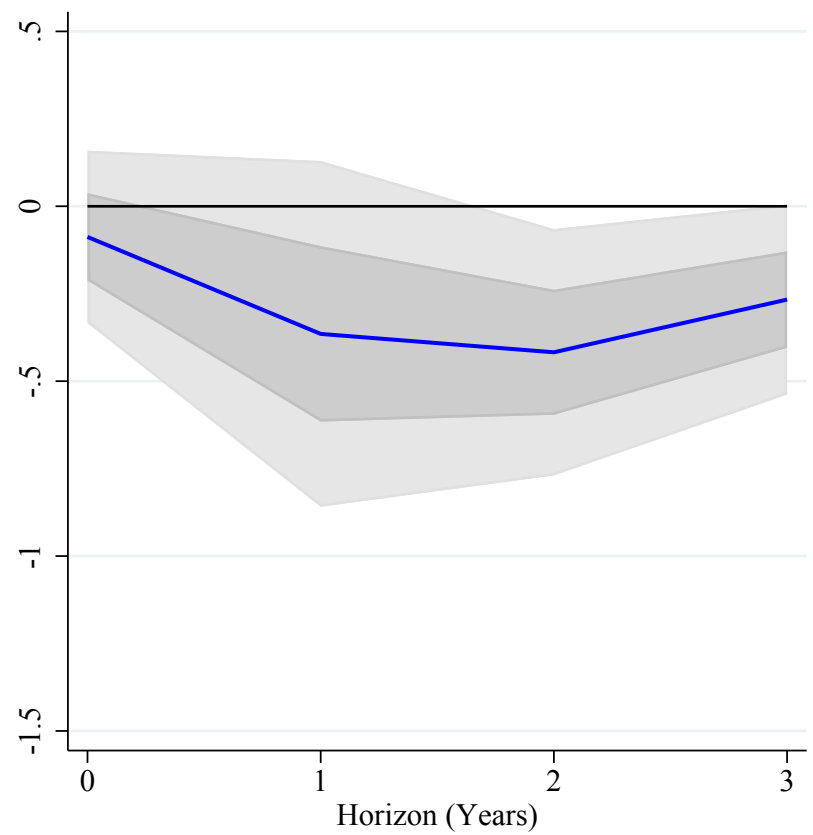

Notes: Vertical axes reported in percent change with respect to the origin. One and two standard deviation confidence bands for each coefficient estimate shown as grey areas. Local projections as specified in equation (1) using two lags of each control described therein. Sample 1978:1-2009:4. See text.

Looking to Panel (b) of Figure 1 highlights the main focus of our analysis. On average, real short term interest rates fall following a fiscal consolidation. To the extent that monetary policy can support the economy when GDP falls, the decline in the real short rate implies that the average fiscal consolidation is associated with monetary accommodation, which is perhaps not unexpected. The exact effect on GDP, however, will depend in the precise degree of accommodation by the monetary authority, in other words the strength of the "monetary offset" at the time. What we see in Figure 1 is only the effect on average. If the fall in the real rate were smaller, for example, we might expect to see a more severe contraction in GDP. Decomposing this average, and characterizing the heterogeneity around it, is therefore the crux of this paper.

In the published paper $F$ is the change in the Cyclically Adjusted Primary Balance, instrumented with the newly constructed fiscal shocks, $f_{i, t}$. In the working paper version, the underlying impulse response functions for GDP following a 1\% movement in the newly constructed fiscal shock are reported. As discussed in Ramey (2016), the 2SLS estimate of the multiplier is equivalent to computing the raw effect on the level of GDP and dividing this by the response of the endogenous fiscal variable (e.g., the CAPB or the fiscal deficit). When we construct fiscal multipliers below we will follow a similar approach by effectively instrumenting the deficit to GDP ratio with the Guajardo, Leigh, and Pescatori (2014) constructed fiscal shocks. 


\section{Decomposing the FISCAL MUltiplier}

In this section we formally motivate and introduce the Blinder-Oaxaca decomposition, show how it can be applied to time-series analysis, and then use it to produce a decomposition of an impulse response function. As a new tool in time-series analysis, some preliminary motivation and explanation is required. In the next section we will then explicitly use this decomposition to quantify how the fiscal multiplier may vary with monetary policy.

\subsection{Preliminary statistical discussion and intuition}

When it comes to investigating causal relationships, randomized controlled trials are generally viewed as the gold standard. We briefly discuss some basic ideas in this paradigm to motivate the local projection decomposition that we introduce later on. Formal statements of any assumptions needed can be found in, e.g., Wooldridge (2001) and Fortin, Lemieux, and Firpo (2011). Later on we provide assumptions for typical macroeconomics applications. Here we focus on the intuition.

Suppose we are interested in the response of an outcome variable, $y$, to a randomly assigned intervention, $f$. Assume $f \in\{0,1\}$ is randomly assigned, at least conditional on controls $x$, and the observed data are generated by the following mixture of unobservable latent variables, $y_{1}$ and $y_{0}$,

$$
y=(1-f) y_{0}+f y_{1}=y_{0}+f\left(y_{1}-y_{0}\right)
$$

That is, the observed random variable $y$ is either the random variable $y_{0}$, which is observed when $f=0$, or it is $y_{1}$ when $f=1$. Note that the observed data belong to one state or the other. One cannot simultaneously observe both states. As is standard, we refer to $y_{0}$ and $y_{1}$ as potential outcomes in the terminology of the Rubin causal model (Rubin, 1974).

These potential outcomes are random variables $y_{j}$ with $j \in\{0,1\}$. Suppose they have unconditional mean $E\left(y_{j}\right)=\mu_{j}$. A natural statistic of interest is $E\left(y_{1}-y_{0}\right)=\mu_{1}-\mu_{0}$, that is, the average difference in the unconditional mean between the treated and the control subpopulations. Although the potential outcomes $y_{1}$ and $y_{0}$ cannot be simultaneously observed, their moments (under random assignment), can be easily calculated.

The potential outcomes approach and its notation can be somewhat new to applied macroeconomists. A few examples can help clarify basic notions. In a randomized controlled trial, a common (strong) ignorability assumption is that $y_{j} \perp f$ for $j=0,1$. This assumption does not imply that $y$ and $f$ are unrelated. Rather, the assumption means that the choice of intervention $f$ is unrelated to the potential outcomes that may happen for a given choice of $f \in\{0,1\}$. Hence a quantity such as $E\left(y_{1} \mid f=0\right)$ is well defined. It refers to the expected value that the random variable $y_{1}$ - from the treated subpopulation - would counterfactually take had it not been exposed to treatment and instead had been placed in the control group. We will use such counterfactual expectations below. 
We might reflect on the strong ignorability condition. It is worth noting that even when this fails in practice, a milder condition of selection on observables, that is, $y_{j} \perp f \mid x$ for $j=0$, I would allow most of the results here to carry through and would be akin to identification based on exclusion restrictions (depending on what is included in $x$ ), using the VAR vernacular. We will expand on this point below.

\subsection{The Blinder-Oaxaca decomposition}

Without loss of generality, we can write $y_{j}=\mu_{j}+v_{j}$ where $E\left(v_{j}\right)=0$, since $E\left(y_{j}\right)=\mu_{j}$ by definition, with $j \in\{0,1\}$. Any heterogeneity in the treated and control subpopulations is therefore relegated to the terms $v_{j}$. Whenever covariates (explanatory variables or, simply, controls) $x$ are available, they are useful to characterize heterogeneity across units (and later for us, across time) and we may assume additivity so that $v_{j}=g(x)+\epsilon_{j}$. As a starting point it is natural to further assume that these covariates enter linearly, so that $v_{j}=(x-E(x)) \gamma_{j}+\epsilon_{j}$. We include the covariates in deviations from their unconditional mean to ensure that $E\left[(x-E(x)) \gamma_{j}\right]=0$, in which case unobserved heterogeneity is such that $E\left(\epsilon_{j}\right)=0$. If observed heterogeneity is well captured by the vector of explanatory

variables and the linearity assumption is correct, then it is also the case that $E\left(\epsilon_{j} \mid x_{j}\right)=0$. That is, the projection of $y_{j}$ onto $x_{j}$ is properly specified.

Researchers are often interested in understanding the overall effect of the intervention on outcomes. The Blinder-Oaxaca decomposition (Blinder, 1973; Oaxaca, 1973) is used often in applied microeconomics for this purpose. It is worth going through its derivation here before later using similar arguments on local projections. These derivations borrow heavily from Wooldridge (2001) and Fortin, Lemieux, and Firpo (2011).

The overall average treatment effect of the intervention can be written as

$$
\begin{aligned}
E\left(y_{1} \mid f=1\right)-E\left(y_{0} \mid f=0\right)= & E\left[E\left(y_{1} \mid x, f=1\right) \mid f=1\right]-E\left[E\left(y_{0} \mid x, f=0\right) \mid s=0\right] \\
= & \{\mu_{1}+E[x-E(x) \mid f=1] \gamma_{1}+\underbrace{E\left(\epsilon_{1} \mid f=1\right)}_{=0}\} \\
& -\{\mu_{0}+E[x-E(x) \mid f=0] \gamma_{0}+\underbrace{E\left(\epsilon_{0} \mid f=0\right)}_{=0}\} .
\end{aligned}
$$

Straightforwardly, by adding and subtracting $E[x-E(x) \mid f=1] \gamma_{0}$, Equation 3 can be rearranged as

$$
\begin{aligned}
E\left(y_{1} \mid f=1\right)-E\left(y_{0} \mid f=0\right)= & \left(\mu_{1}-\mu_{0}\right) \\
& +E[x-E(x) \mid f=1]\left(\gamma_{1}-\gamma_{0}\right) \\
& +\{E[x-E(x) \mid f=1]-E[x-E(x) \mid f=0]\} \gamma_{0} .
\end{aligned}
$$

Equation 4 contains three interesting terms. The first $\mu_{1}-\mu_{\mathrm{o}}$ is the difference in the unconditional means of the treated and control subpopulations. We refer to it as the direct effect of an intervention. 
The second term $E[x-E(x) \mid f=1]\left(\gamma_{1}-\gamma_{0}\right)$ reflects changes in how the covariates affect the outcome due to the intervention. We will refer to this term as the indirect effect of intervention. For example, a background in mathematics may translate into a higher salary for workers assigned to take additional training in computer science, but may not be otherwise helpful if there is no complementarity between both knowing mathematics and computer science. Notice that $E[x-E(x) \mid f=1] \gamma_{0}$ explores the salary of workers with a given background in mathematics, had they been counterfactually assigned not to take the additional training in computer science. A natural hypothesis we will be interested in testing is $H_{0}: \gamma_{1}-\gamma_{0}=\mathbf{o}$. Failure to reject the null suggests that the effect of the covariates on the outcome is not affected by the intervention. Crucially, it turns out that, up to now, traditional estimates of impulse responses have implicitly assumed this to be the case. Later on, we will see that such a hypothesis plays a critical role in evaluating impulse response state-dependence. Note that, in a proper randomized control trial, the indirect effect should be zero on average, but this does not mean that $\gamma_{1}-\gamma_{0}=\mathbf{o}$. The covariates $x$ will still influence the way in which treatment affects the outcomes for particular values of $x$.

The final term $\{E[x-E(x) \mid f=1]-E[x-E(x) \mid f=0]\} \gamma_{0}$ reflects how, all else equal, the effect of the intervention may be driven simply by differences in the average value of the explanatory variables between the treated and control subpopulations. We will call this term the composition effect. A test of the null $H_{\mathrm{O}}: E[x-E(x) \mid f=1]-E[x-E(x) \mid f=0]=\mathbf{0} \rightarrow H_{\mathrm{O}}: E[x \mid f=1]-E[x \mid f=0]=\mathbf{0}$ is useful to determine the balance of the distribution of covariates between treated and control subpopulations. In a proper randomized control trial, there should be no differences and the null would not be rejected. A rejection of the null instead indicates that selection into treatment could depend on the value of the covariates and hence introduce selection bias in the estimation. Small sample measurement of the composition effect can be used to sterilize the biased average treatment effect estimate that would result otherwise.

In practice, a natural way to obtain each term in the decomposition of Equation 4 in a finite sample would be to estimate the following regression, using Equation 2 as the springboard,

$$
y_{i}=\mu_{\mathrm{O}}+\left(x_{i}-\bar{x}\right) \gamma_{\mathrm{o}}+f_{i}\left\{\beta+\left(x_{i}-\bar{x}\right) \boldsymbol{\theta}\right\}+\omega_{i}
$$

where $\hat{\beta}=\hat{\mu}_{1}-\hat{\mu}_{\mathrm{O}}$ is an estimate of the direct effect; $\hat{\boldsymbol{\theta}}=\hat{\gamma}_{\mathbf{1}}-\hat{\gamma}_{\mathbf{0}}$ and hence $\left(\overline{\boldsymbol{x}}_{\mathbf{1}}-\overline{\boldsymbol{x}}\right) \hat{\boldsymbol{\theta}}$ is an estimate of the indirect effect. The notation $\bar{x}_{1}$ refers to the sample mean of the covariates for the treated units. A test of the null $H_{\mathrm{O}}: \boldsymbol{\theta}=\mathbf{0}$ is a test of the null that the indirect effect is zero on average (although the specific realizations may have non-zero effects, as we shall see). In that case the covariates affect the outcomes in the same way, on average whether or not a unit is treated. Finally, the term $\left(\bar{x}_{1}-\bar{x}_{0}\right) \gamma_{0}$ is an estimate of the composition effect and a natural balance test is a test of the null $H_{\mathrm{O}}: E(x \mid f=1)-E(x \mid f=0)=0$. Note that the error term is $\omega_{i}=\epsilon_{i, \mathrm{O}}+f_{i}\left(\epsilon_{1, i}-\epsilon_{\mathrm{O}, i}\right)$. Under the maintained assumptions, it has mean zero conditional on covariates. 


\subsection{Decomposing local projection responses}

The methods discussed in Section 3.1 and Section 3.2, while common in applied microeconomics research, have not permeated macroeconomics as much. In this section we show that local projections offer a natural bridge between literatures and hence offer a more detailed understanding of impulse responses, the workhorse of applied macroeconomics research.

In order to move from the preliminary statistical discussion to a time series setting in which to investigate impulse responses, we define the outcome random variable observed at a horizon $h$ periods after the intervention as $y(h)$, where a typical single observation from a finite sample of $T$ observations is denoted $y_{t+h}$.

As before, we begin with a binary policy intervention (i.e., the treatment) denoted $f \in\{0,1\}$ where a typical single observation from a finite sample is denoted $f_{t}$. A vector of observable predetermined variables is denoted $x$, where a typical single observation from a finite sample is denoted $x_{t}$. Note that $x$ includes contemporaneous values and lags of a vector of variables including the intervention, as well as lags of the (possibly transformed) outcome variable, among others. Moreover, define $y=(y(0), y(1), \ldots, y(H))$ or when denoting an observation from a finite sample, $\boldsymbol{y}_{t}=\left(y_{t}, y_{t+1}, \ldots y_{t+H}\right)$.

A natural starting point regarding the assignment of the policy intervention is to follow Angrist, Jordà, and Kuersteiner (2018), whose selection on observables assumption we restate here for convenience:

Assumption 1. Conditional ignorability or selection on observables. Let $\boldsymbol{y}_{f}$ denote the potential outcome that the vector $y$ can take on impact and up to $H$ periods after intervention $f \in\{0,1\}$. Then we say $f$ is randomly assigned conditional on $\boldsymbol{x}$ relative to $\boldsymbol{y}$ if:

$$
y_{f} \perp f \mid x \quad \text { for } f=f(x, \eta ; \phi) \in\{0,1\} ; \phi \in \Phi
$$

The conditional ignorability assumption makes explicit that the policy intervention $f$ is itself a function the observables $x$, unobservables $\eta$, and a parameter vector $\boldsymbol{\phi}$. It means that $\boldsymbol{y}_{f} \perp \eta$, that is, the unobservables are random noise. Moreover, we assume that $\phi$ is constant for the given sample considered. In other words, we rule out variation in the rule assigning intervention.

Although such a general statement of conditional ignorability provides a great deal of flexibility (see Angrist et al., 2018), a simpler assumption can be made when considering a linear framework in the analysis that follows. In particular, for our purposes, the following assumption will suffice:

Assumption 2. Conditional mean independence. Let $E\left(\boldsymbol{y}_{f}\right)=\boldsymbol{\mu}_{f}$ for $f \in\{0,1\}$ so that, without loss of generality, $\boldsymbol{y}_{f}=\boldsymbol{\mu}_{f}+\boldsymbol{v}_{f}$. As before, we now assume linearity so that $\boldsymbol{v}_{f}=(\boldsymbol{x}-E(\boldsymbol{x})) \Gamma_{f}+\boldsymbol{\epsilon}_{f}$. Because of the dimensions of $\boldsymbol{y}_{f}$, notice that $\Gamma_{f}$ is now a matrix of coefficients with row dimension $H+1$. Then,

$$
E\left(\boldsymbol{y}_{f} \mid x\right)=\boldsymbol{\mu}_{f} ; \quad E\left(\boldsymbol{v}_{f}\right)=\mathbf{0} ; \quad E\left(\boldsymbol{\epsilon}_{f} \mid \boldsymbol{x}\right)=\mathbf{0} ; \quad \text { for } f \in\{0,1\}
$$


Based on Assumption 2, local projections can be easily extended to have the same format as expression Equation 5. Specifically,

$$
y_{t+h}=\underbrace{\mu_{\mathrm{o}}^{h}+\left(x_{t}-\bar{x}\right) \gamma_{\mathrm{o}}^{h}+f_{t} \beta^{h}}_{\text {usual local projection }}+\underbrace{f_{t}\left(x_{t}-\bar{x}\right) \boldsymbol{\theta}^{h}}_{\begin{array}{c}
\text { Blinder-Oaxaca } \\
\text { extension }
\end{array}}+\omega_{t+h} ; \quad \text { for } h=0,1, \ldots, H ; t=h, \ldots, T .
$$

Thus, relative to the usual specification of a local projection, the only difference is the additional Blinder-Oaxaca term, $f_{t}\left(x_{t}-\bar{x}\right) \theta^{h}$. As a result of this simple extension, estimates of the components of an impulse response at any horizon $h$ can be calculated in parallel fashion to Section 3.2, with

$$
\begin{aligned}
\text { Direct effect: } & \hat{\mu}_{1}^{h}-\hat{\mu}_{\mathrm{o}}^{h}=\hat{\beta}^{h}, \\
\text { Indirect effect: } & \left(\overline{\boldsymbol{x}}_{\mathbf{1}}-\overline{\boldsymbol{x}}\right)\left(\hat{\gamma}_{\mathbf{1}}^{h}-\hat{\gamma}_{\mathbf{0}}^{h}\right)=\left(\overline{\boldsymbol{x}}_{\mathbf{1}}-\overline{\boldsymbol{x}}\right) \hat{\boldsymbol{\theta}}^{h}, \\
\text { Composition effect: } & \left(\overline{\boldsymbol{x}}_{\mathbf{1}}-\overline{\boldsymbol{x}}_{\mathbf{0}}\right) \hat{\gamma}_{\mathbf{o}}^{h}
\end{aligned}
$$

where $\bar{x}_{f}$ refers to the sample mean of the controls in each of the subpopulations $f \in\{0,1\}$.

In a time series context, one requires an assumption about the stationarity of the covariate vector $x$. Without it, calculating means for the treated and control subpopulations would not be a well-defined exercise. In a typical local projection it is not necessary to make such an assumption because the parameter of interest is $\hat{\beta}^{h}$ and all that is required for inference is for the projection to have a sufficiently rich lag structure to ensure that the residuals are stationary. Consequently, we make an additional assumption here, as follows:

Assumption 3. Ergodicity. The vector of covariates $x_{t}$ - which can potentially include lagged values of the (possibly transformed) outcome variable and the treatment, as well as current and lagged values of other variables — is assumed to be a covariance-stationary vector process ergodic for the mean (Hamilton, 1994).

Ergodicity ensures that the sample mean converges to the population mean. Assuming covariancestationarity is a relatively standard way to ensure that this is the case. More general assumptions could be made to accommodate less standard stochastic processes. However, covariance-stationarity and ergodicity are sufficiently general to include many of the processes which are commonly observed in practice.

\subsection{Beyond binary policy interventions}

Policy interventions sometimes vary from one intervention to the next. Think of fiscal policy and the different amounts by which taxes and spending can be raised or lowered. Call it the problem of choosing the policy dose. When the set of alternative doses is finite and small, it is easy to extend the analysis from the Section 3.1 by defining $f \in\left\{f^{\circ}, f^{1}, \ldots, f^{J}\right\}$ where $f^{\circ}$ refers to the benchmark case (e.g., $\left.f^{\mathrm{O}}=\mathrm{o}\right)$ against which alternative treatments $\left\{f^{1}, \ldots, f^{J}\right\}$ are compared. An example of such an approach in a time series setting can be found in Angrist, Jordà, and Kuersteiner (2018). 
Investigating dose responses in this manner is advantageous. No assumption is made on possible non-linear and non-monotonic effects of the treatment on the outcome. We know that, for example, drugs administered in certain doses can be quite beneficial, but doubling the dose does not mean that the benefit doubles - in fact, most drugs become lethal at higher and higher doses!

When doses vary continuously, say $-\infty<\delta<\infty$, extending the standard ignorability assumptions of the potential outcomes approach becomes impractical. There would be infinite potential outcomes (one for each value of the dose received) and, hence, we would be unable to recover parameters from finite samples. However, with little loss of generality, we can assume that variation in doses affect outcomes through a policy scaling factor $\delta=\delta(x)$. The dependence of $\delta$ on $x$ captures policy considerations and also allows for non-monotonic effects in the choice of dose.

Under this more general form of $\delta$, Equation 2 now requires a further assumption regarding the choice of dose given policy intervention in order for us to be able to identify the policy effect. A natural assumption is conditional mean independence of dose given assignment, stated as follows:

Assumption 4. Conditional mean independence of dose given assignment. As in Assumption 2, let $\boldsymbol{y}_{f}=\boldsymbol{\mu}_{f}+\boldsymbol{v}_{f}$ with $\boldsymbol{v}_{f}=(\boldsymbol{x}-E(\boldsymbol{x})) \Gamma_{f}+\boldsymbol{\epsilon}_{f}$. Define the scaling factor $\delta(\boldsymbol{x})$. Then we assume that:

$$
E\left[\delta(x) y_{1} \mid x\right)=\delta(x) \mu_{1}
$$

That is, $E\left[\delta(x) \epsilon_{1}\right]=0$, since $E\left[\delta(x)(x-E(x)) \Gamma_{f} \mid x\right]=0$.

(Notice that no further assumption is necessary regarding $\boldsymbol{y}_{\mathrm{O}}$.)

Assumption 4 is a useful reminder of the conditions required to explore impulse responses in general settings. Because this paper introduces several novel elements, we henceforth restrict the analysis to the case where $\delta(x)=\delta$ and leave for a different paper a more thorough investigation of non-monotonicities in dose assignment. This is a standard assumption in applied macroeconomics and it simply says that doubling the dose will double the response. We think that given the typical policy interventions observed, and given that outcomes are usually analyzed in logarithms — so that policy interventions have proportional effects - this is a very reasonable starting point.

Based on this simplifying assumption, Equation 5 can now be extended as follows,

$$
y_{t+h}=\mu_{\mathrm{o}}^{h}+\left(x_{t}-\bar{x}\right) \gamma_{\mathrm{o}}^{h}+\delta_{t} \beta^{h}+\delta_{t}\left(x_{t}-\bar{x}\right) \theta^{h}+\omega_{t+h} ; \quad \text { for } h=0,1, \ldots, H ; t=h, \ldots, T,
$$

using the convention $\delta_{t}=\mathrm{o}$ if $f_{t}=\mathrm{o}$. The parameters $\beta^{h}$ and $\boldsymbol{\theta}^{h}$ have the same interpretation as in expression (7) in that scaling by the dosage allows one to interpret the coefficients on a per-unit-dose basis. In the fiscal policy application, this would correspond, say, to a $1 \%$ of GDP tightening in the fiscal balance. Dividing by, say, -2 would then equivalently generate responses to a $0.5 \%$ of GDP stimulus instead. A constant scaling factor also implies symmetry of responses. Importantly, the direct, indirect, and composition effects can be estimated using estimates from the extended local projections in Equation 9 in the same way as in the case of a binary treatment as explained in expression Equation 8. 


\subsection{Blinder-Oaxaca impulse response functions}

An interesting feature of the Blinder-Oaxaca decomposition is that it allows us to evaluate the indirect effect of the policy intervention at a particular value of the controls. Auerbach and Gorodnichenko (2012) find asymmetric effects of government spending changes based on whether the economy is in a boom or a bust. Jordà and Taylor (2016) find similar asymmetries using the Guajardo, Leigh, and Pescatori (2014) dataset. In the monetary policy literature, for example, Angrist, Jordà, and Kuersteiner (2018) show that monetary policy loosening is less effective at stimulating the economy than tightening. Tenreyro and Thwaites (2016) find asymmetric effects based on whether the economy is in a boom or a bust. Jordà, Schularick, and Taylor (2020), using a different approach, find that low inflation environments and large output gaps seem to dull stimulative policy.

We now show how these, and many other scenarios, can be easily entertained in our setup by using the Blinder-Oaxaca decomposition and the same set of parameter estimates. In particular, notice that for a specific value of $x$, say, $x^{*}$, we have, since $E\left(\delta \epsilon_{1} \mid x^{*}\right)=0$,

$$
\begin{aligned}
E\left(y_{1} \mid x^{*}, \delta\right)-E\left(y_{\mathrm{O}} \mid x^{*}, s=0\right) & =\delta \mu_{1}+\delta\left[x^{*}-E(x)\right] \gamma_{1}-\left\{\mu_{\mathrm{O}}+\left[x^{*}-E(x)\right] \gamma_{\mathrm{o}}\right\} \\
& =\beta+\delta\left[x^{*}-E(\boldsymbol{x})\right] \boldsymbol{\theta} .
\end{aligned}
$$

Hence, based on the same estimates as those of the extended local projection in Equation 9, given a specific value of $x^{*}$, the implied estimate of the impulse response at that value is

$$
\delta \hat{\beta}+\delta\left(x^{*}-\bar{x}\right) \hat{\theta}
$$

and this holds for a given $\delta$, since the composition effect is zero. This happens because $\left(x^{*}-\bar{x}\right)$ is the same for the treated and control subpopulations. Here we rely on the residuals having zero mean conditional on $x$. It is also important to note that because identification usually centers on treatment assignment rather than identification for the controls, conditioning on certain values of $x$ can only be interpreted from a partial equilibrium perspective. Nevertheless, because in time series applications lagged values of $x$ are pre-determined with respect to the policy intervention, they are a legitimate description of a state of the world in which we envisage conducting the counterfactual experiment.

Several remarks are worth stating. First, although it is a convenient tool to investigate statedependence, given the assumptions we have made, the Blinder-Oaxaca decomposition lacks enough information to evaluate how the impulse response indirect effect would vary if, say, the control $x_{j t}$ increased by one unit. The reason is that we have made no assumptions about the assignment of the controls. We cannot infer causal effects about them without further assumptions. The measured indirect effect for the $j^{\text {th }}$ control could be polluted by any correlation with other controls, for example. This issue potentially faces all papers in the literature on state-dependence in macroeconomics. The Blinder-Oaxaca decomposition allows for a more systematic analysis of state dependence and clarifies how these identification issues arise. In the next section we will introduce an approach to explicitly address this issue in the context of monetary-fiscal interactions. 
Second, several hypotheses of interest underlie Equation 8. Absence of direct effects can be assessed by evaluating $H_{\mathrm{O}}: \beta^{h}=0$; absence of indirect effects with $H_{\mathrm{O}}: \boldsymbol{\theta}^{h}=0$; and absence of composition effects with $H_{\mathrm{O}}: \gamma_{\mathrm{O}}^{h}=\mathrm{o}$. All of these null hypotheses only require standard Wald tests directly obtainable from standard regression output given our maintained assumptions. Thus formal tests of economically meaningful hypotheses are easily reported as we now show in an application.

\section{How DOES THE FISCAL MULTIPLIER DEPEND ON MONETARY POLICY?}

In the previous section we have shown that the Blinder-Oaxaca decomposition of an impulse response function implies an indirect effect from a policy treatment if the intervention affects how other variables influence outcomes. In this section we apply this logic to examine how the effects of a fiscal policy intervention are influenced by monetary policy. As noted in the introduction, empirical fiscal multipliers are typically average treatment effects. At any point in time, the specific impact of a fiscal intervention may, however, depend on monetary policy. Instead, the average effect estimated in the existing literature reflects the average response of monetary policy, as illustrated in Figure 1. The Blinder-Oaxaca decomposition suggests a way to decompose these effects. To make this idea concrete, we sketch a simple motivating framework for thinking about the indirect effect and the identification issues noted in Section 3. In the previous section we gave the example where a background in mathematics may translate into a higher salary for workers assigned to take additional training in computer science. In our current context, the idea is that a less activist monetary regime may translate into a larger recession following fiscal treatment.

\subsection{Motivating example and identification}

To formalize the interaction we have in mind consider the following, stylized, setup. In Section 5, we will confirm that this approach works well using simulations from a standard New Keynesian DSGE model. Let some outcome $y_{i, t}$, e.g., GDP growth in country $i$ at time $t$, depend on fiscal treatment $f_{i, t}$ and the choice of the real interest rate $r_{i, t}$. All variables as expressed relative to their means. Furthermore, suppose the interest rate is set by a monetary authority following a rule. Interest rates are set to offset the negative effects of shocks to GDP, including changes in fiscal policy. Specifically,

$$
\begin{aligned}
& y_{i, t}=\delta_{f} f_{i, t}+\delta_{r} r_{i, t}+u_{i, t}^{y}, \\
& r_{i, t}=\bar{\Theta}^{f} f_{i, t}+\Theta_{i}^{f} f_{i, t}+\Theta^{y} u_{i, t}^{y}+u_{i, t}^{r},
\end{aligned}
$$

where $\delta_{f}$ measures the fiscal multiplier holding interest rates constant. In the data this cannot typically be estimated because interest rates are likely to endogenously respond to fiscal treatment, as is the case in Equation 13. This equation says that monetary policy responds to fiscal interventions but, in the way this rule is written, the degree of monetary accommodation could vary across

countries. $\bar{\Theta}^{f}$ reflects the average response across all countries and $\Theta_{i}^{f}$ is the idiosyncratic component. 
Monetary policy also potentially responds to other economic shocks, captured by the term $u_{i, t^{y}}^{y}$. Combining Equation 12 and Equation 13 yields

$$
y_{i, t}=\left(\delta_{f}+\delta_{r} \bar{\Theta}^{f}\right) f_{i, t}+\delta_{r} \Theta_{i}^{f} f_{i, t}+\delta_{r} u_{i, t}^{r}+\left(1+\delta_{r} \Theta^{y}\right) u_{i, t}^{y} .
$$

On the assumption that treatment $f_{i, t}$ is randomly assigned (as should be the case if the fiscal shocks are exogenous), the first term illustrates that the reduced-form estimate of the fiscal multiplier depends on the average monetary response in the data, $\delta_{r} \bar{\Theta}^{f}$. In other words, $\delta_{f}, \delta_{r}$ and $\bar{\Theta}_{f}$ are not separately identified using the fiscal shock alone. The second term captures heterogeneity in the interest rate response. Note that Equation 14 has the form of the Blinder-Oaxaca decomposition in Equation 7. In this simple case without any other controls, $f$ (the policy treatment) in Section 3.2 corresponds to $f_{i, t}$ here and $\left(x_{i, t}-\bar{x}\right)=\Theta_{i}^{f}$. The indirect effect is then $\delta_{r} \Theta_{i}^{f}$. Since the total response (ignoring the composition effect) is simply the direct effect plus the indirect effect, we can consider experiments around the average effect by arbitrarily varying the indirect effect.

The decomposition in Section 3 shows that, without further assumptions, we cannot interpret the coefficients on the $x$ variables as causal. This, of course, has implications for all existing papers studying state dependence. Following the Blinder-Oaxaca intuition, our idea is that the strength of the monetary offset varies with the monetary regime: fiscal stimulus may be less effective if the monetary policymaker is a hawk. To implement this we need a proxy for the monetary regime, i.e., here the parameter $\Theta_{i}^{f}$, that can be used for identification of the monetary offset. We take inspiration from Nakamura and Steinsson (2014) and Guren, McKay, Nakamura, and Steinsson (2020), who use the differential sensitivity of regions to more aggregate fluctuations as an identification strategy. In our approach, we use the differential sensitivity of interest rates to fiscal treatment across countries. 9 Our strategy will therefore exploit the panel dimension of the dataset and, more specifically, crosscountry variation in $\Theta_{i}^{f}$ to trace out the importance of the monetary offset. ${ }^{10}$ The first step is to estimate a variant of Equation 13 allowing the coefficient on the fiscal shock to vary by country. The cross-country $\Theta_{i}^{f}$ can then be used as a state variable in the estimation of equation $14 .{ }^{11}$

The identification assumption underlying this approach is that there is variation in the average response of monetary policy to shocks across countries but that this variation is not, on average, correlated with other factors that make the economy more sensitive to fiscal policy. In Section 5 we will show, using a relatively standard New Keynesian model, that this approach successfully recovers the strength of the monetary offset where the main degree of heterogeneity across country is variation in the monetary regime.

${ }^{9}$ We are therefore using cross-country heterogeneity in the country interest rate response to identified country-level shocks. This differs from Nakamura and Steinsson (2014) and Guren, McKay, Nakamura, and Steinsson (2020) who exploit differential local sensitivity to common aggregate or regional fluctuations.

${ }^{10}$ More generally we could exploit the responsiveness of interest rates to the economy, as we will discuss further in Sections 5 and 6.

${ }^{11}$ Note that in our application, $f_{i, t}$, should be thought of as a random time-country disturbance. Because this should be uncorrelated with other shocks - at any spatial level - there is no issue omitting the other terms from equation 13 when estimating the proxy $\Theta_{i}^{f}$. 
An important issue is that, to use the notation above for illustration, $\delta_{f}$ might vary across countries for other reasons and this might be responsible for the apparent sensitivity of interest rates to fiscal policy. More generally, this would be the case if there is heterogeneity in the multiplier on average across countries for non-monetary reasons, and if monetary policy responds to fiscal treatment indirectly.

Three remarks should be made about this. First, this issue would tend to attenuate the strength of the monetary offset, so at a very minimum, our results can be seen as a lower bound. This is because larger contractionary forces would typically be associated with bigger — not smaller movements - in interest rates. In other words, a seemingly weak monetary policy response would be the result of a smaller underlying fiscal multiplier. Instead, we find that a less activist monetary regime is associated with much larger fiscal multipliers. Second, in the practical application of the Blinder-Oaxaca decomposition we will also allow for a sizable degree of unspecified statedependence by admitting indirect effects via each of the controls already included in Section 2. Finally, two generalizations of our approach can be used to explicitly deal with this concern. The first relies on estimating a more generic Taylor Rule, rather than the response of the economy to fiscal treatment directly. In Section 6 we show that, even in the presence of heterogeneity in the multiplier, this works well and produces empirical estimates that are similar to our baseline findings. The drawback of this approach is complexity and having to take a stand on the form of the Taylor Rule. We therefore still favor our main specification. The second generalization introduces controls for other cross-country time-invariant factors that might be correlated with the average sensitivity of interest rates to fiscal policy. In our context, it might be that some countries use a different tax/spending mix when implementing a consolidation. To the extent that tax and spending multipliers differ, this could be influencing our results. Section 6 shows how to explicitly control for this, and that the main findings are robust.

\subsection{The fiscal-monetary multiplier}

By applying the Blinder-Oaxaca decomposition, and using the motivating logic from the previous subsection, we now examine how the fiscal multiplier varies with monetary policy. For exposition, we repeat - and augment - the main regression specification here,

$$
y_{i, t+h}=\mu_{\mathrm{o}}^{h}+\left(x_{i, t}-\bar{x}_{i}\right) \gamma_{\mathrm{o}}^{h}+f_{i, t} \beta^{h}+f_{i, t}\left(x_{i, t}-\bar{x}_{i}\right) \theta_{x}^{h}+f_{i, t} \Theta_{i, h}^{f} \theta_{f}^{h}+\omega_{i, t+h},
$$

where $f_{i, t}$ is the policy treatment, in our case the fiscal shocks identified by Guajardo, Leigh, and Pescatori (2014). The outcome variable $y_{i, t+h}$ will either be the cumulative percentage change in GDP, i.e. $y_{i, t+h}=\left(G D P_{i, t+h}-G D P_{i, t-1}\right) / G D P_{i, t-1}$, or the cumulative change in the deficit $(D)$ relative to initial GDP, $y_{i, t+h}=\left(D_{i, t+h}-D_{i, t-1}\right) / G D P_{i, t-1} \cdot{ }^{12}$ The $\beta^{h}$ coefficients estimate the conventional impulse response function for the percentage change in the level of GDP or the deficit relative to GDP.

\footnotetext{
${ }^{12}$ This ensures the ratio of these two IRFs can be interpreted as a multiplier, as discussed below.
} 
By estimating this sequence of local projections we can estimate the direct, indirect, and composition effects. Unlike in Section 3.2, however, our goal is to conduct experiments where we vary the indirect effect coming from monetary policy. In the full specification, $x$ includes all the controls from Section 2: two lags of the growth rate of GDP, the deficit to GDP ratio, the change in the real interest rate and, following Jordà and Taylor (2016), the output gap. To capture global time-varying factors, we include world GDP growth as discussed earlier.

To obtain a cross-country proxy for the monetary regime, we estimate $\Theta_{i, h}^{f}$ by regressing the change in the nominal policy interest rate from $t-1$ to $t+h$ on the fiscal consolidation variable $f_{i, t}$, allowing the coefficient to vary by country. ${ }^{13}$ This gives a country specific sensitivity of nominal policy rates to fiscal policy. In the second stage regression, in keeping with the Blinder-Oaxaca decomposition, the variable $\Theta_{i, h}^{f}$ refers to these coefficients relative to the average. ${ }^{14}$ Armed with this proxy for the monetary regime, Equation 15 is then used to study the response of GDP but including $\Theta_{i, h}^{f}$ as an additional state variable. ${ }^{15}$

Figure 2 reports the main results from this exercise. Panel (a) shows the percentage response of GDP following a $1 \%$ of GDP fiscal consolidation (as measured by Guajardo, Leigh, and Pescatori, 2014). The central blue line in the fan reports the direct effect which, roughly, should be compared to the results from the linear model is Figure 1. As in Figure 1, GDP falls by around 1\% over the course of 2-3 years. To examine how the effect varies with monetary policy, the gray lines then conduct experiments where we vary the indirect effect estimated using the Blinder-Oaxaca decomposition from Equation 15. In particular, Figure 2 shows a range of scenarios where we vary $\Theta_{i, h^{\prime}}^{f}$ the sensitivity of interest rates to fiscal policy. In keeping with the Blinder-Oaxaca formulation $\Theta_{i, h}^{f}$ - like all state variables - is expressed relative to its mean. The results therefore consider how the multiplier varies as we change the degree of monetary offset relative to the average degree of accommodation in the sample (captured in the direct effect). In Figure 2 the size of the circular marker indicates a tighter/more contractionary monetary policy. We vary $\Theta_{i, h}^{f}$ by one standard deviation, which produces real interest rate variation of the order of 1oobps on average over the period (see Appendix 7). In the face of a fiscal consolidation (a negative shock to GDP), this means a

${ }^{13}$ We also include the lagged change in the policy rate to capture persistence in the policy rate and include country fixed effects. For the baseline results we keep this specification parsimonious, which helps improve the precision of the estimates. We have also reproduced the main results considering more elaborate specifications with further controls. The results for how the multiplier varies with monetary policy are very similar, so we maintain the parsimonious specification for the baseline results. Part of the reason for this robustness is that we are constructing a proxy for the sensitivity of interest rates to shocks rather than trying to precisely identify the coefficients of the Taylor Rule.

${ }^{14}$ This ensures that our experiments below are relative to the "typical" average response of policy rates in the sample. The average of the coefficients from the first stage regression also accords with conventional wisdom about how monetary policy tends to loosen following a fiscal consolidation on average. For example, in years $0,1,2$ and 3 the average value of the country level coefficients is $-0.3,-0.6,-0.7$ and -0.5 respectively.

${ }_{15}$ Since we are interested in the dynamic causal effect via impulse response functions, this step is run for each $h$. The right hand side of Equation 15 therefore contains $f_{i, t} \Theta_{i, h}^{f} \theta_{f}^{h}$. This is like interacting fiscal treatment at time $t$ with the predicted subsequent response of the real interest rate: $f_{i, t} \Theta_{i, h}^{f}$ is the fitted value for the future interest rate response from the preliminary regression. 
Figure 2: Policy experiments varying the response of monetary policy

(a) GDP Response (\%)

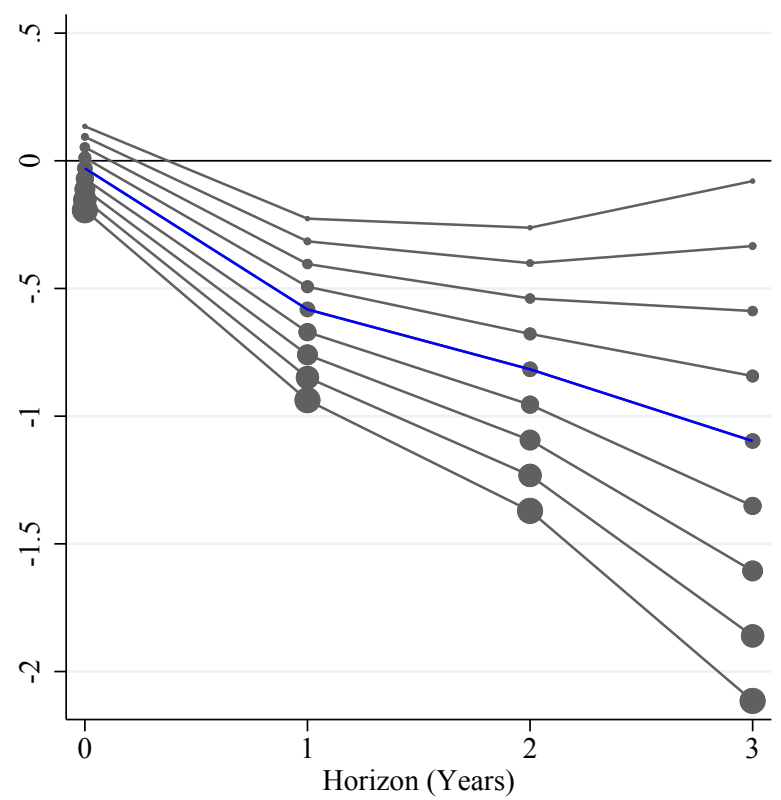

(b) Indirect Effect for GDP $h=3$

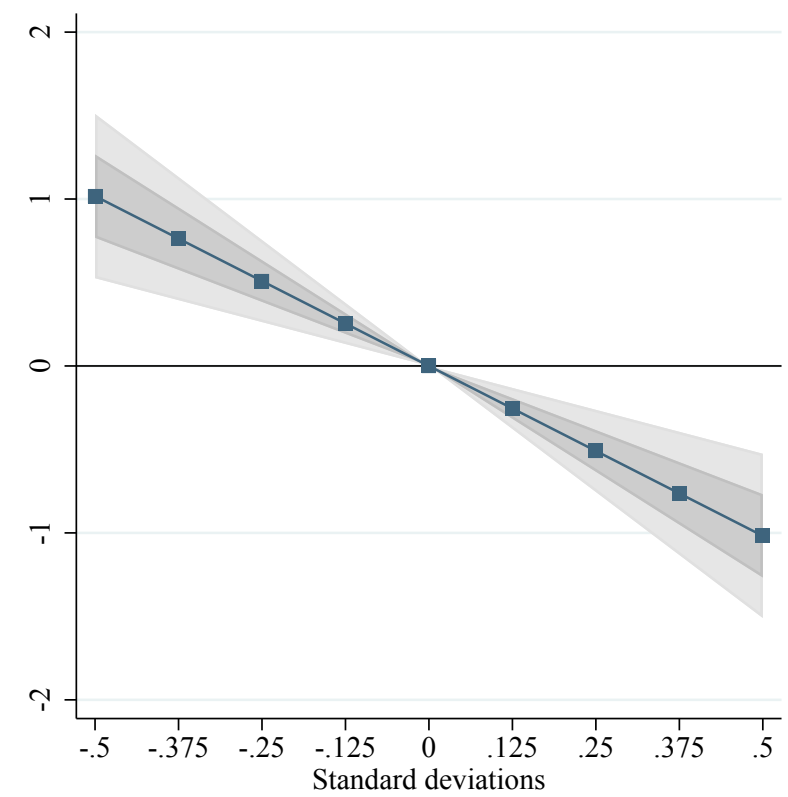

Notes: Panel (a) shows how the response of GDP varies with the degree of monetary policy accommodation. The blue lines report the direct effect, which should be compared to the average effect in Figure 1. The gray lines consider experiments which vary the degree of monetary accommodation. A larger marker indicates a tighter monetary policy scenario. Panel (b) plots the indirect effect on GDP for the peak effect at $h=3$. The figure illustrates the effect of the monetary-fiscal interaction relative to the average multiplier in the full sample. This also allows us to formally test whether the indirect effect is statistically significant. The light and dark gray areas refers to a confidence interval of two and one standard deviations.

less activist monetary policy which does not cut the policy rate as aggressively. This should increase the multiplier and this is indeed what is shown in Figure 2. As monetary policy becomes less accommodative, the multiplier becomes larger. Appendix Figure A.4 reports the associated figure for the response of the real interest rate. As expected tighter monetary policy is associated with less accommodation in terms of the real interest rate. In fact, at the extreme, for regimes where the nominal rate is least responsive, the response of the real rate can even become positive.

Panel (b) of Figure 2 shows the indirect effect on GDP for the peak effect at $h=3$ and the standard errors. This figure therefore shows the effect of the monetary-fiscal interaction relative to the average multiplier in the full sample (the central blue line in Panel (a)). This also allows us to formally test whether the indirect effect is statistically significant. The light and dark gray areas refer to a confidence interval of two and one standard deviations. As shown in the figure, for less accommodative monetary policy regimes, the negative effect on GDP is nearly $1 \%$ larger than in the baseline and this effect is statistically significant. In Appendix Table A.I we report the precise coefficient estimates for $\beta^{h}$ (the direct effect), $\theta_{f}^{h}$ (the strength of the indirect effect) and the standard errors at all horizons. ${ }^{16}$

\footnotetext{
${ }^{16}$ For presentational reasons, panel (a) of Figure 2 does not display the standard errors but Appendix Figure A.3 also visually shows that the direct effect (the blue line) is statistically significant.
} 
Figure 3: Cumulative fiscal multiplier by monetary response

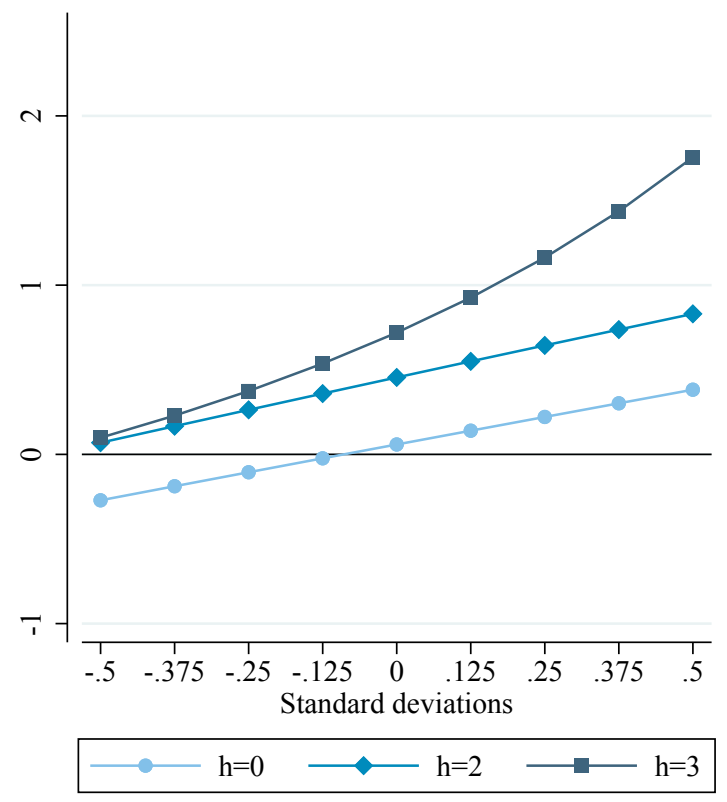

Notes: This chart shows the cumulative fiscal multiplier from each scenario in Figure 2. This is computed as the cumulative sum of the GDP response relative to the cumulative deficit to GDP response (based on Appendix Figure A.2). Each line refers to a different horizon, $h$. As in Figure 2, $h$ goes from the current year $h=0$ to the third year after the shock $h=3 . h=1$ is omitted to avoid overcrowding the figure.

Although these responses for GDP can be roughly interpreted as a measure of the fiscal multiplier, the $f_{i, t}$ shocks may be noisy measures of the true policy change (see, e.g., Mertens and Ravn, 2013). As a statistic, the fiscal multiplier is typically defined as the \$ movement in GDP for a one \$ change in fiscal policy. Following Ramey (2016), this object can be computed empirically be estimating the effect on GDP and dividing by the associated change in the deficit relative to GDP. It is therefore instructive to also consider what happens to the deficit to GDP ratio to get a sense of the magnitude of the fiscal intervention in the data. The response of the deficit may also vary with the behavior of monetary policy, for example higher interest rates and lower demand could make it harder to reduce the deficit. The response of the deficit relative to GDP is shown in Appendix Figure A.2. A $1 \%$ fiscal consolidation (as measured by Guajardo, Leigh, and Pescatori (2014)) takes some time to have its full effect. The deficit to GDP ratio moves by around $0.5 \%$ in the current year, and is around $1 \%$ lower from the next year onwards. This path also depends on monetary policy, although in these experiments, there is not much state-dependence in the deficit to GDP ratio until the later years.

Dividing the results in Figure 2 Panel (a) by the associated change in the deficit is also equivalent to the 2SLS estimate of the multiplier using the Guajardo, Leigh, and Pescatori (2014) shocks as instruments for the deficit to GDP ratio. In our case this is a useful way of representing the multiplier because different experiments produce different paths of the deficit. This approach therefore harmonizes the policy interventions across the scenarios. In computing the multiplier, we 
would also like to consider the differential effect on the deficit and GDP at all horizons. Since GDP is a flow, one can think of the cumulative lost GDP in dollars relative to the cumulative improvement in the deficit, also in dollars. This measure, known as the cumulative, integral, or present-value multiplier, is increasingly seen in the literature, as recommended by Uhlig (2010) and Ramey (2016) .

Figure 3 converts the state-dependent IRFs from Figure 2 and Figure A.2 into cumulative multipliers at different horizons. The cumulative multiplier is reported on the y-axis. As before, on the x-axis we vary $\Theta_{i, h}^{f}$ from -0.5 to +o.5 standard deviations. The three lines report the multiplier at different horizons in the impulse response function. Note that the o point on the $x$-axis corresponds to the average treatment effect usually estimated in linear models. Interestingly, this is around or below 1 at all horizons. As monetary policy becomes more inert (rates are cut less aggressively in the face of falling demand), the multiplier rises. In these experiments the multiplier varies from around zero to nearly 2 . Thus, in any fiscal intervention, the fiscal multiplier crucially depends on the monetary response. Interestingly, magnitudes around 2 are close to Keynes' original prediction of 2.5 (Keynes, 1936).

Before concluding this section it is worth making a few remarks about the flexibility of this approach. Note that, in principle, by allowing fiscal policy interventions to have different marginal effects depending on the whole set of controls $x$, we can handle state-dependence in a very flexible and multivariate manner. This also has important implications for the existing literature which has typically studied the effects of one dimension in isolation (or one at a time).

\section{THEORETICAL ANALYSIS}

In this section we show how our empirical approach and findings can be rationalized in a simple theoretical macro framework. In particular, we do two things. First, we show how variation in the monetary policy rule affects the fiscal multiplier in the model. This is, of course, already known in the theoretical literature but motivates the exercise we have in mind. Second, we simulate data from the model for a hypothetical set of "countries" where each country differs in how monetary policy responds to inflation. ${ }^{17}$ This environment theoretically captures the identification assumptions made in the previous section.

To illustrate the usefulness of the Blinder-Oaxaca decomposition, we simulate data from the theoretical model for our hypothetical set of countries and run exactly the same empirical estimation approach used in the previous section on data simulated from the model. We show that the BlinderOaxaca decomposition performs notably well at capturing how the fiscal multiplier varies with the degree of monetary accommodation. ${ }^{18}$

\footnotetext{
${ }^{17}$ We use the term "country" loosely here. In this simple example these are simply cross sectional units with different degrees of monetary accommodation.

${ }^{18}$ Our goal is to illustrate how the Blinder-Oaxaca approach identifies the importance of monetary-fiscal interactions for the size of the fiscal multiplier. This section does not develop a theoretical framework to quantitatively rationalize the magnitudes found in the previous section.
} 
The results in the previous section already have some important theoretical implications. For monetary policy to affect the fiscal multiplier, the model needs some form of nominal rigidity. This motivates our focus on the New Keynesian class of models. Second, to generate a wider range of multipliers the model needs to have some other rigidities beyond the simple textbook model. For simplicity, we follow Gal'1, López-Salido, and Vallés (2007) and Leeper, Traum, and Walker (2017) and include two types of households, one group who fully optimize and another group who act in a rule of thumb manner. ${ }^{19}$ In the presence of nominal rigidities, this allows the model to produce a range of different results for the multiplier, some of which are larger than 1 (see Leeper, Traum, and Walker, 2017). To keep the model simple, a contractionary fiscal policy is modeled as a persistent cut in government spending. We will assume the savings from this policy experiment are rebated lump-sum back to the saver households. ${ }^{20}$

\subsection{Model environment}

In this subsection we sketch the main, and very standard, features of the model we use. More details are provided in the Appendix.

The economy is populated by a continuum of households. A share $1-\mu$ of the households can save (or borrow) freely and fully optimize their intertemporal consumption/savings choices. These households choose consumption, hours worked, and bond holdings to maximize expected lifetime utility subject to their budget constraint.

We refer to these households as saver households, and their choices with a superscript $S$. In linearized form, the saver household's first order conditions can be re-arranged. First, the change in consumption can be written as

$$
E_{t} \Delta \hat{c}_{t+1}^{S}=\frac{1}{\sigma}\left(\hat{i}_{t}-E_{t} \hat{\pi}_{t+1}\right),
$$

which is the standard Euler from the representative agent model, where $\hat{\pi}_{t}$ is the log change in the price of the consumption good $P_{t}$ and $\hat{i}_{t}$ is the policy interest rate, both in deviations from steady state. $\hat{c}_{t}^{S}$ is consumption of the saver household in percentage deviations from steady state. The labor supply condition is

$$
\hat{w}_{t}=\hat{c}_{t}^{S}+\psi \hat{n}_{t}^{S}
$$

where $\hat{w}_{t}$ is the real wage and $\hat{n}_{t}^{S}$ is hours worked, both in percentage deviations from steady state. The inverse Frisch elasticity is $\psi$.

We assume that the remaining share $\mu$ of households are rule-of-thumb decision-makers in the sense that they have no access to bonds $B$ and consume all their labor income. We refer to these

\footnotetext{
${ }^{19}$ Again, this is purely expositional and, as discussed in Leeper, Traum, and Walker (2017), a number of modeling devices can be used to generate positive consumption effects that produce larger multipliers following a fiscal stimulus.

${ }^{20}$ Alternatively we could have assumed that the government repays debt owned by the saver households but, because saver households finance the government, a form of Ricardian equivalence applies here and there is no need to model debt explicitly.
} 
households a non-saver households, and denote their choices with a superscript $N .^{21}$ Thus,

$$
C_{t}^{N}=w_{t} N_{t}^{N}
$$

Total consumption in this economy is therefore equal to

$$
C_{t}=\mu C_{t}^{N}+(1-\mu) C_{t}^{S}
$$

To rationalize price stickiness, there are two types of firms. An intermediate good $y_{t}(j)$ is produced using a constant returns to scale production technology $y_{t}(j)=A n_{t}(j)$ under imperfect competition. We normalize TFP, $A$, to 1 . Intermediate goods are turned into final goods $Y_{t}$ by competitive final goods firms using the standard CES production function $Y_{t}=\left(\int_{0}^{1} y_{t}(j)^{\frac{\epsilon-1}{\epsilon}} d j\right)^{\epsilon /(\epsilon-1)}$. Final goods are either purchased by households or government, i.e. $Y_{t}=C_{t}+G_{t}$ where $G_{t}$ is government consumption expenditure. All varieties of intermediate good are substitutable with one another with an elasticity of demand $\epsilon$ and the demand curve for variety $y_{t}(j)$ is given by $y_{t}(j)=\left(\frac{p_{t}(j)}{P_{t}}\right)^{-\epsilon} Y_{t}$, which the intermediate goods firm takes as given.

Intermediate goods firms set prices and choose labor demand to minimize costs. The representative firm's decision problem is standard in the New Keynesian literature so we only report this in the appendix. With probability $\theta$ a firm is unable to change its price and maintains the same price as it had in $t-1$. With probability $1-\theta$ the firm is able to fully reset its price. The equilibrium conditions from the firm side lead to a standard dynamic pricing relationship. In linearized form this is the familiar New Keynesian Phillips Curve where inflation depends on expected future inflation and real marginal cost (which is closely related to the output gap),

$$
\hat{\pi}_{t}=\beta E_{t} \hat{\pi}_{t+1}+\tilde{\kappa} \widehat{m c}_{t}
$$

where $\tilde{\kappa}=\frac{1}{\theta}(1-\theta)(1-\beta \theta), \theta$ is the probability of having a fixed price, and $\beta$ is the household's discount factor. $\widehat{m c}_{t}$ is real marginal cost in percentage deviations from steady state.

Fiscal policy is simply described by an exogenous, persistent stream of government purchases. Written in percentage deviations from steady state,

$$
\hat{g}_{t}=\rho_{g} \hat{g}_{t-1}+e_{t}
$$

The government redistributes the savings from lower government spending back to the saver households in a lump sum manner. The government budget constraint is simply $G_{t}=T_{t}$ but similar results would be obtained if we formally allowed for government debt (owned by the savers).

Monetary policy follows a simple Taylor Rule. The nominal interest rate $\hat{i}_{t}$, written in deviations from steady state, is set relative to inflation. Importantly, we will think of this rule as varying across

\footnotetext{
${ }^{21}$ These households still make an intratemporal consumption and labor choice. The intratemporal labor supply equation is the same as for the saver household and, given the competitive nature of the labor market, both types of household face the same real wage.
} 
Figure 4: Theoretical state dependence versus Blinder-Oaxaca estimates

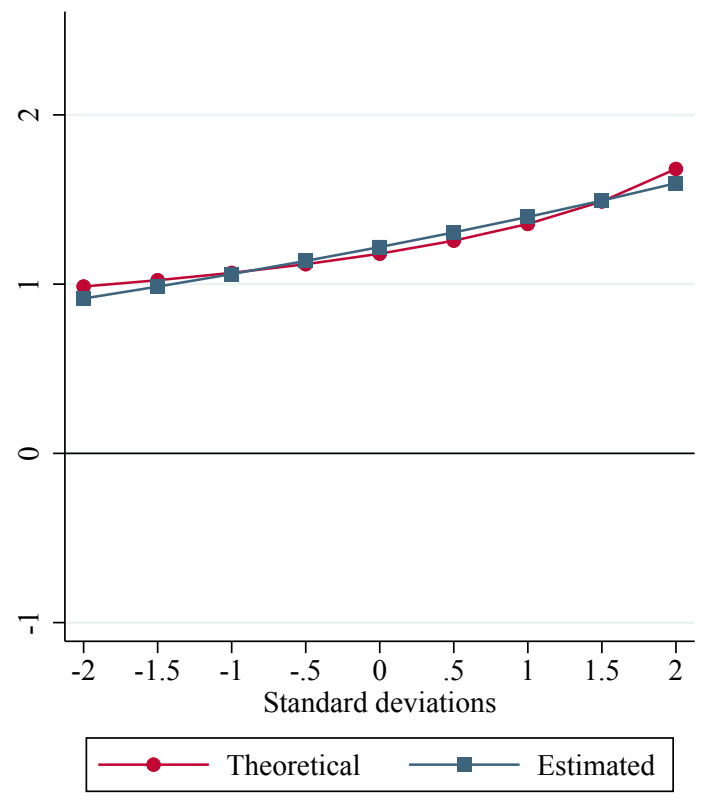

Notes: This chart shows how the peak cumulative fiscal multiplier varies with the monetary policy response both in the theoretical model and when the effect is estimated on simulated data. The red circles show the true theoretical variation in the simulated dataset. The blue squares show the empirical estimates obtained by using our Blinder-Oaxaca decomposition estimates on data simulated from the model. We simulate the model for 2000 periods, discarding the first $10 \%$.

country but where each country operates as a closed economy. The policy rule is therefore

$$
\hat{i}_{t}=\rho_{i} \hat{i}_{t-1}+\left(1-\rho_{i}\right) \phi^{c} \hat{\pi}_{t}
$$

where $c$ denotes the "country" of interest and the policy rules therefore allows for different countries to have different monetary responses to fiscal consolidation attempts.

\subsection{The Blinder-Oaxaca decomposition}

The model is solved using standard linearization-based methods. We calibrate $\psi=1.7$, implying a Frisch elasticity of around o.6. The probability of having a fixed price is set to $\theta=0.85$. The household's discount factor $\beta=0.99$. The persistence of government spending $\rho_{g}=2 / 3$ and interest smoothing $\rho_{i}=0.75$. We set the share of hand to mouth households $\mu$ to $30 \%$. Following Leeper, Plante, and Traum (2010), we set the government consumption share to $8 \%$.

We then simulate data from the model for different values of $\phi^{c}$, starting at 1 (so monetary policy satisfies the Howitt-Taylor Principle). To relate the model experiment to the empirical set-up in the previous section, we regard each simulation as data for a different country (each a closed economy for simplicity). We then estimate the Blinder-Oaxaca decomposition on the simulated model data. The results are show in Figure 4 . 
Figure 4 shows two lines. The red line with circles shows how the peak cumulative fiscal multiplier - computed exactly as in the data - varies with $\phi^{c}$. The blue line with squares shows the Blinder-Oaxaca decomposition-implied fiscal multiplier. As in the previous section, the response of interest rates to the fiscal shock is estimated by country and this coefficient is used as a state variable in the Blinder-Oaxaca decomposition. The horizontal axis refers to standard deviations of this object. ${ }^{22}$ The figure shows that the Blinder-Oaxaca decomposition captures the monetary interaction in the simulated data very well. ${ }^{23}$

Two important results flow from this exercise. First, it shows that the identification approach outlined in the previous section, using differential sensitivity of interest rates to fiscal shocks across countries to identify how the fiscal multiplier varies with the systematic part of monetary policy, works well. Second, the Blinder-Oaxaca decomposition is a very effective way of isolating statedependence in the fiscal multiplier. Finally note that, although the model is deliberately simple, more elaborate features and/or changes to the calibration would simply change the quantitative magnitudes in Figure 4, not the two main results mentioned here.

\section{RobUSTNESS AND EXTENSIONS}

In this section we subject our approach to several robustness checks and extensions.

\subsection{An alternative proxy for the monetary regime}

As discussed above, our baseline strategy works well to quantify the importance of the monetary offset when variations in the monetary regime are the main source of heterogeneity in the fiscal multiplier across countries. In this section, we relax this assumption using an alternative approach to proxy for the monetary regime. Rather than constructing a proxy by regressing policy rates on the fiscal shock directly, this section makes use of a more conventional Taylor Rule-type approach.

To fix ideas, consider the policy rule from the model,

$$
\hat{i}_{t}=\rho_{i} \hat{i}_{t-1}+\left(1-\rho_{i}\right) \phi^{c} \hat{\pi}_{t},
$$

Note that we are not necessarily trying to identify the specific parameters of the Taylor Rule. Rather, we are trying to obtain a proxy for the sensitivity of interest rates to the economy. We can therefore estimate a more reduced form expression:

$$
\hat{i}_{t}=\alpha_{i} \hat{i}_{t-1}+\alpha_{\pi}^{c} \hat{\pi}_{t}
$$

where there is a monotonic mapping between the cross-country variation in $\phi^{c}$ and $\alpha_{\pi}^{c}$.

\footnotetext{
${ }^{22}$ Note that, Blinder-Oaxaca indirect effect captures a non-linear function of the model's parameters so there is monotonic but not one-to-one mapping between $\phi^{c}$ and the indirect effect estimated in the data.

${ }^{23}$ The only discrepancy is that the model's solution is slightly non-linear in $\phi^{c}$.
} 
In Appendix Figure A.5 we verify this approach using the model. In particular, we introduce a second source of cross-country heterogeneity in the multiplier by allowing the share of hand to mouth households to vary from $25 \%$ to $35 \% .{ }^{24}$ To estimate equation 19 we regress nominal policy rates on their lag and inflation, but where we instrument inflation with its lag. ${ }^{25}$ This instrumentation step is not important in this specific example, but we could imagine a more general rule that contains monetary policy shocks (as could be the case in the real world). Appendix Figure A. 5 shows that, even in the presence of additional multiplier heterogeneity, this strategy recovers the underlying importance of monetary offset in the model.

Appendix Figure A.6 now conducts the same experiment in the data. The difference with the baseline results is that we regress policy rates on lagged policy rates and inflation (instrumented), rather than the simpler specification using the fiscal shock. The results are broadly similar to the baseline findings. The drawback of this approach is that it requires making assumptions about the arguments of the Taylor Rule, so it not as transparent or easy to implement. Still, we see this as an important robustness check. ${ }^{26}$

\subsection{Tax- versus spending-led consolidations}

It is possible that countries differ in the composition of the fiscal consolidation. For example, some countries may rely more on tax increases than spending cuts. The fiscal multiplier literature has often noted differences in spending versus tax multipliers. Furthermore, Guajardo, Leigh, and Pescatori (2014) find that tax-based consolidations are more contractionary.

This could affect our results in the following way. Suppose, for example, that tax multipliers are larger than those for spending (for reasons unrelated to monetary policy, as is the case in some macro models). Different policies might then induce different relative movements in GDP and interest rates. If countries differ in their average reliance on tax increases versus spending cuts, this could conceivably be captured in the $\Theta_{i}^{f}$ in our baseline approach.

The flexibility of the Blinder-Oaxaca specification allows us to investigate and control for this effect. Specifically, we construct a country-specific measure of the average propensity to use tax increases versus spending cuts. ${ }^{27}$ We then interact this cross-country characteristic with the fiscal treatment $f_{i, t}$, essentially adding it as an additional Blinder-Oaxaca state variable. The residual variation in $\Theta_{i}^{f}$ is then being used to examine the monetary offset. ${ }^{28}$

\footnotetext{
${ }^{24}$ This is simply an illustration, this exercise could also be done for other structural parameters such as the Frisch elasticity, the degree of price stickiness etc.

${ }^{25} \mathrm{~A}$ step that is relatively common in the estimation of Taylor Rules.

${ }^{26}$ As an extension we considered a factor approach where inflation above is replaced by the first principal component of inflation and the output gap. This is one way to incorporate more arguments in the rule but estimate a single parameter to act as the proxy for the monetary regime. The results are very similar.

27In particular, we calculate the share of consolidation episodes that are tax-led by country.

${ }^{28}$ Guren, McKay, Nakamura, and Steinsson (2020) follow a similar logic to focus on residual variation in their sensitivity instrument, albeit in a different setting where the variation of concern is a time-region effect. The strategy used above could also be applied to rule out other cross-country concerns, although these types
} 
Figure 5: Policy experiments: time fixed effects

(a) Response of GDP (\%)

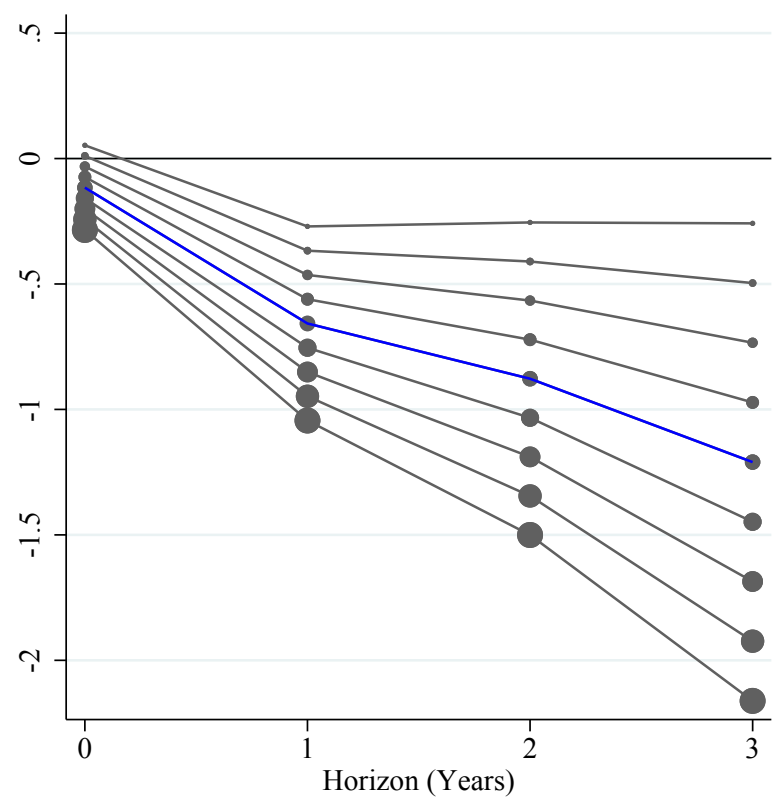

(b) Cumulative fiscal multiplier by monetary response

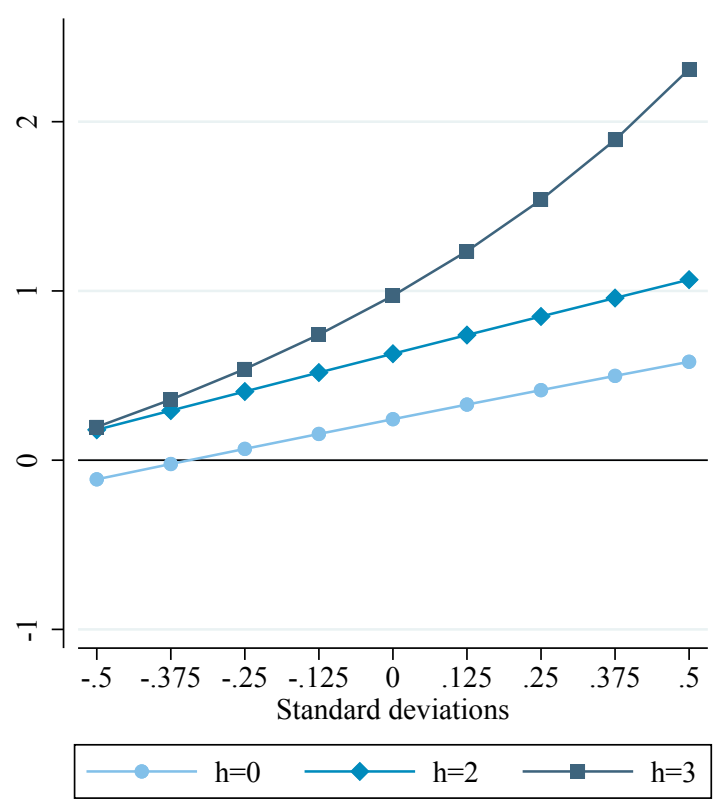

Notes: Panel (a) shows how the response of GDP varies with the degree of monetary policy accommodation. The blue lines report the direct effect. The gray lines consider experiments which vary the degree of monetary accommodation. A larger marker indicates a tighter monetary policy scenario. Panel (b) reports the associated cumulative fiscal multiplier. Relative to baseline Figure 2 and Figure 3, the specification in these figures include time fixed effects rather than world GDP growth.

The results of this exercise are shown in Appendix Figure A.7. The estimated monetary offset is very similar to the baseline case.

\subsection{Global factors}

In the baseline specification we included world GDP growth to capture time varying global factors that might account for the timing of particular fiscal consolidations. In the original Guajardo, Leigh, and Pescatori (2014) paper, the authors use time fixed effects as a more general way of capturing global factors. Earlier we noted that this seems to come at the cost of precision in our specification, but in this section we re-estimate our main results for the monetary-fiscal multiplier using time fixed effects rather than world GDP growth.

The results are shown in Figure 5. These figures are very similar to the baseline specification in Figures 2 and 3. Our use of world GDP growth does not, therefore, affect our main results.

of issues are also dealt with in a more general sense in the previous subsection using a different approach. 
Figure 6: Policy experiments: longer lag structure

(a) Response of GDP (\%)

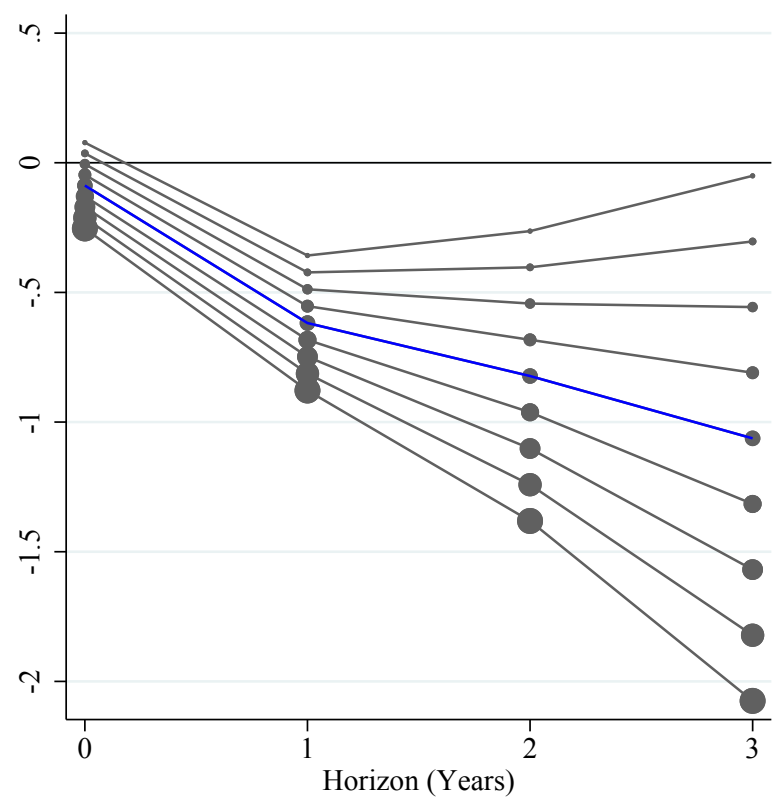

(b) Cumulative fiscal multiplier by monetary response

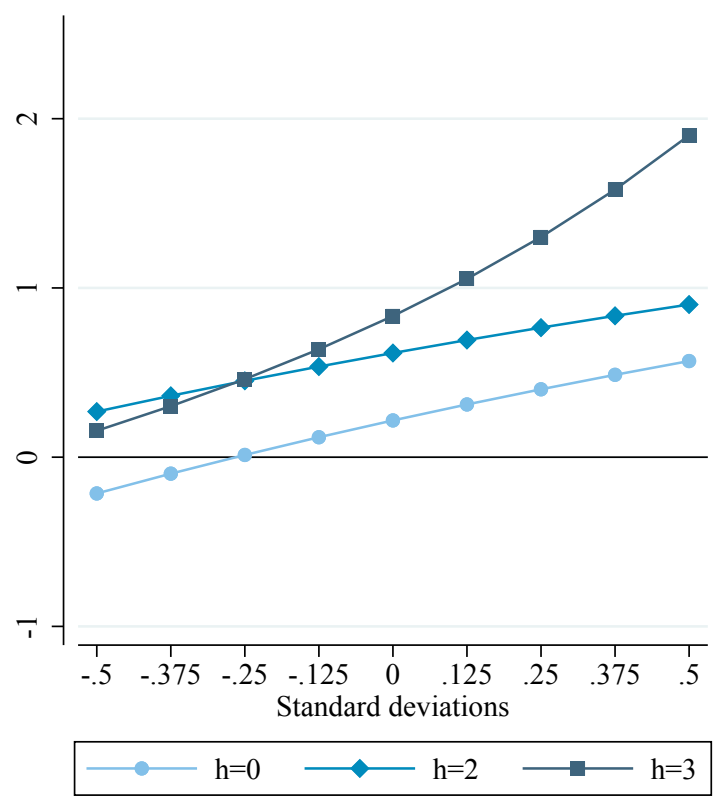

Notes: Panel (a) shows how the response of GDP varies with the degree of monetary policy accommodation. The blue lines report the direct effect. The gray lines consider experiments which vary the degree of monetary accommodation. A larger marker indicates a tighter monetary policy scenario. Panel (b) reports the associated cumulative fiscal multiplier. Relative to baseline Figure 2 and Figure 3, the specification in these figures include 3 lags of all controls in $x$.

\subsection{Lag structure}

If the fiscal shocks reflect purely random variation, the choice of additional controls should not affect the main set of estimates. In small samples however, serial correlation could potentially be an issue. As a further robustness check we show that the main results are not overturned by using a slightly longer lag structure for the controls. In the baseline results we chose two years of lags. Note that, relative to standard empirical papers using quarterly data, this is already controls for a reasonable degree of persistence. We also face a trade-off in that longer lag structures lead to loss of data and more parameters to be estimated.

That said, we re-run our main results using three years of lags (equivalent, of course, to 12 quarters of lags in typical macro papers). Figure 6 shows that the results are very similar to the baseline findings in Figures 2 and 3.

\subsection{Monetary-fiscal interactions using shocks}

To further corroborate the magnitudes found above, in this section, we consider a different approach to studying monetary-fiscal interactions. Instead of relying on variation in the response of interest rates to fiscal policy across countries, this section uses an approach based on monetary policy shocks. 
To motivate the approach consider the following modified version of the motivating example presented in Section 4.1,

$$
\begin{aligned}
& y_{i, t}=\delta_{f} f_{i, t}+\delta_{r} r_{i, t}+u_{i, t}^{y}, \\
& r_{i, t}=\Theta_{y} y_{i, t}+\Theta_{f} f_{i, t} y_{i, t}+u_{i, t}^{r} .
\end{aligned}
$$

For simplicity, assume the fiscal intervention is binary and $f_{i, t} \in[0,1]$. Relative to the earlier motivating example, the main difference is the specification of the policy rule. The sensitivity of interest rates to fiscal policy does not vary across country, but it does vary with the type of shock. During episodes of fiscal treatment, the monetary authority may respond to output fluctuations differently than in other periods. In the formulation above, this is captured by the $\Theta_{f}$ term, which is only relevant in periods of fiscal treatment. Note that, when there is no fiscal treatment, $f_{i, t}=0$.

We can, again, combine these expressions to create a reduced form equation. Given the binary nature of this example, we can then inspect the reduced form in the case of treatment, $f_{i, t}=1$ and no treatment, $f_{i, t}=0$. The resulting equation for estimation can be written as:

$$
y_{i, t}=\beta_{f} f_{i, t}+\beta_{r} u_{i, t}^{r}+\beta_{r f} u_{i, t}^{r} f_{i, t}+u_{i, t}^{y}
$$

where

$$
\begin{aligned}
\beta_{r} & =\frac{\delta_{r}}{1-\delta_{r} \Theta_{y}}, \\
\beta_{f} & =\frac{\delta_{f}}{1-\delta_{r}\left(\Theta_{y}+\Theta_{f}\right)}, \\
\beta_{r f} & =\frac{\delta_{r}}{1-\delta_{r}\left(\Theta_{y}+\Theta_{f}\right)}-\beta_{r} .
\end{aligned}
$$

The third term on the right hand side of Equation 22 captures the indirect effect from the interaction of monetary and fiscal policy. The amount of accommodative monetary policy is captured by the size of the monetary shocks $u_{i, t}^{r}$ (since these capture the policy stance relative to what would have been expected given the rule). The indirect effect captures the fact that, less accommodative monetary policy may translate into a larger recession during periods of fiscal treatment.

In estimating Equation 22 the technical challenge is that we do not observe $u_{i, t}^{r}$ directly and commonly constructed proxies for $u_{i, t}^{r}$ are usually only available for countries like the United States. To our knowledge, there is no consistent cross-country dataset of monetary policy shocks. In this section, as a robustness check, we therefore rely on a simple approach to validate the results in the previous section.

First, using a panel ordered probit, we predict the probability of observing an interest rate change based on two lags of GDP growth, inflation, the lagged change in the policy rate, and world GDP growth. We are implicitly assuming a common policy rule across countries. Monetary policy 
Figure 7: Policy experiments: an alternative approach

(a) Response of GDP (\%)

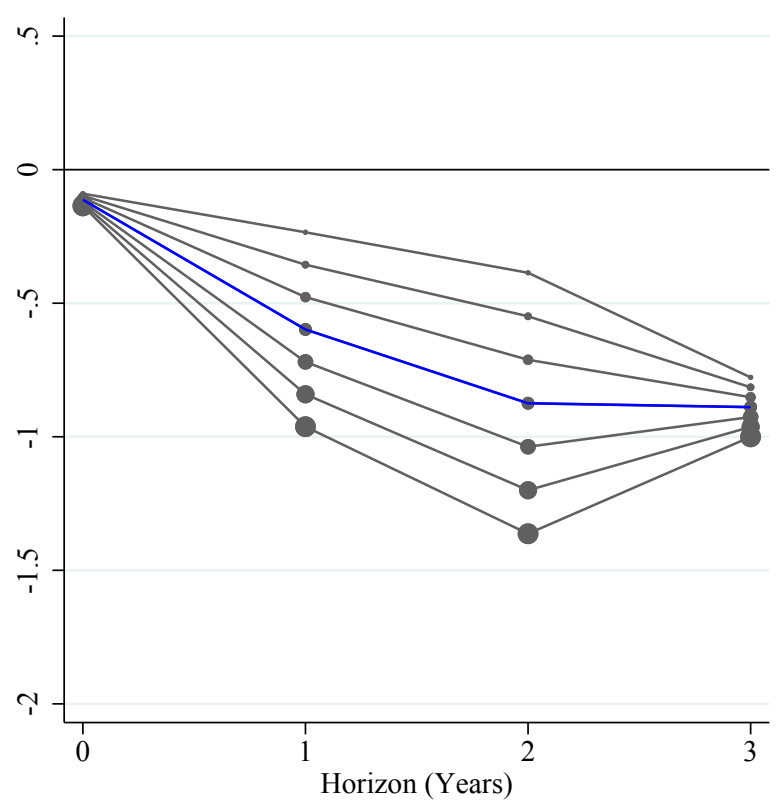

(b) Cumulative fiscal multiplier by monetary response

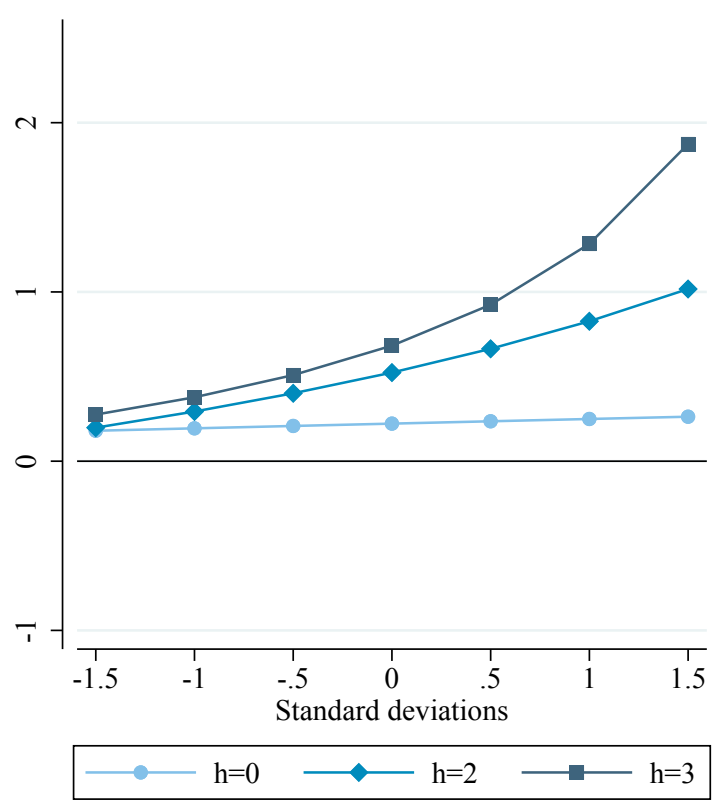

Notes: Panel (a) shows how the response of GDP varies with the degree of monetary policy accommodation. The blue lines report the direct effect. The gray lines consider experiments which vary the degree of monetary accommodation. A larger marker indicates a tighter monetary policy scenario. Panel (b) reports the associated cumulative fiscal multiplier. Relative to baseline Figure 2 and Figure 3, this figure is produced using an alternative approach to monetary-fiscal interactions, as discussed in the text.

shocks are then constructed as follows,

$$
u_{i, t}^{r}=\Delta i_{t}-\left(p_{-1} \times-1+p_{0} \times 0+p_{+1} \times 1\right),
$$

where $i_{t}$ is the nominal policy rate and the $p$ terms are the predicted probabilities of a rate cut, no change or an increase. This approach therefore attempts to remove the predictable component of monetary policy. As in the previous section, the Blinder-Oaxaca decomposition is estimated from the following regression,

$$
y_{i, t+h}=\mu_{\mathrm{o}}^{h}+\left(x_{i, t}-\bar{x}_{i}\right) \gamma_{\mathrm{O}, x}^{h}+u_{i, t+h}^{r} \gamma_{\mathrm{O}, r}^{h}+f_{i, t} \beta^{h}+f_{i, t}\left(x_{i, t}-\bar{x}_{i}\right) \boldsymbol{\theta}_{x}^{h}+f_{i, t} u_{i, t+h}^{r} \theta_{r}^{h}+\omega_{i, t+h},
$$

The main difference from the previous section is that the future stance of monetary policy during the consolidation episode is captured by the deviation of the policy from what was expected, i.e., the shock term $u_{i, t+h}^{r}$.

Figure 7 shows the results. Once again, the first panel shows the effect on GDP on average (blue line), and for tighter and looser monetary policy during the consolidation episode (gray lines). We consider experiments from -1.5 standard deviation shocks to +1.5 standard deviation shocks. We use a wider range for this experiment as a one-standard deviation shock produces smaller variations in interest rates. Episodes with tighter monetary policy are associated with a much larger fall in GDP. 
In Figure A.8, the deficit to GDP ratio also improves by less in these more contractionary episodes. In Figure 7 Panel (b), we therefore report the cumulative fiscal multiplier. The multiplier rises to nearly 2 when monetary conditions are tight.

\subsection{Other forms of state-dependence}

Our regressions contain a number of other state variables and the Blinder-Oaxaca decomposition allows us to consider how the fiscal multiplier varies along each of these dimensions while controlling for the other states. In the literature, state dependence is often investigated by considering one dimension at a time, although typical macro variables that are often used to define the state are likely to be highly correlated. For example, boom periods are likely to be correlated with periods of high inflation, high house prices, and potentially high private credit growth.

Figure 8 shows how the multiplier varies according to each of the other macro controls in our regressions, holding the other variables constant. The other variables are the output gap, the change in the fiscal deficit to GDP ratio, World GDP growth and the size of the fiscal consolidation. ${ }^{29}$

Figure 8 shows that along each of these dimensions, once we control for the other variables simultaneously, there is only sizable state dependence by the size of the output gap. This confirms results in the existing literature, such as Auerbach and Gorodnichenko (2012) and Jordà and Taylor (2016), that fiscal multipliers tend to be larger in periods of low aggregate demand. To the extent that a large change in the deficit to GDP ratio is associated with fiscal stress, our results do not suggest a smaller multipliers in these states. Further, the multiplier does not seem to be smaller for larger consolidations, which was one regularity considered in the expansionary fiscal consolidations literature.

\section{CONCLUSION AND POLICY IMPLICATIONS}

This paper has shown that using the Blinder-Oaxaca decomposition from applied microeconomics in a local projections framework, the impulse response can be decomposed into (1) the direct effect of the intervention on the outcome; (2) the indirect effect due to changes in how other covariates affect the outcome when there is an intervention; and (3) a composition effect due to differences in covariates between treated and control subpopulations. This decomposition provides convenient way to evaluate the effects of policy, state-dependence, and balance conditions for identification.

A natural application of this logic is in the area of monetary-fiscal interactions. The fiscal multiplier is a key statistic for understanding how fiscal policy changes might stimulate or contract the macroeconomy. The size of the multiplier has been a subject of intensive debate since the Global Financial Crisis in 2008. But, despite the importance of this object, there is still much disagreement about existing empirical estimates. A large literature has focused on tackling the

\footnotetext{
${ }^{29}$ Our main regression also includes GDP growth. The results are very similar to those using the output gap and are thus omitted for brevity.
} 
Figure 8: Other forms of state dependence in the fiscal multiplier

(a) Output gap

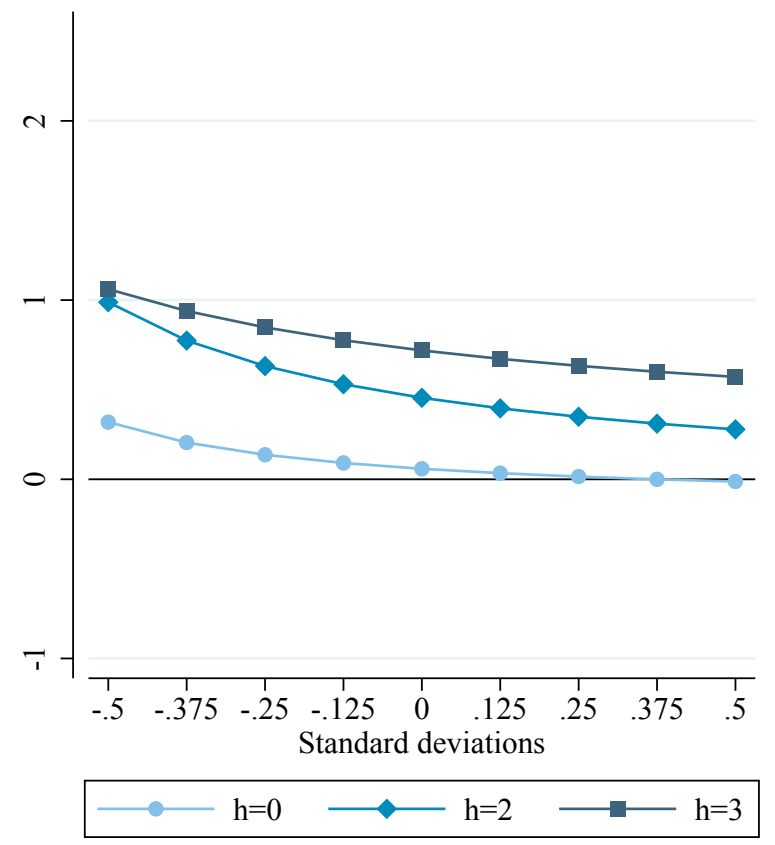

(c) Size of the consolidation

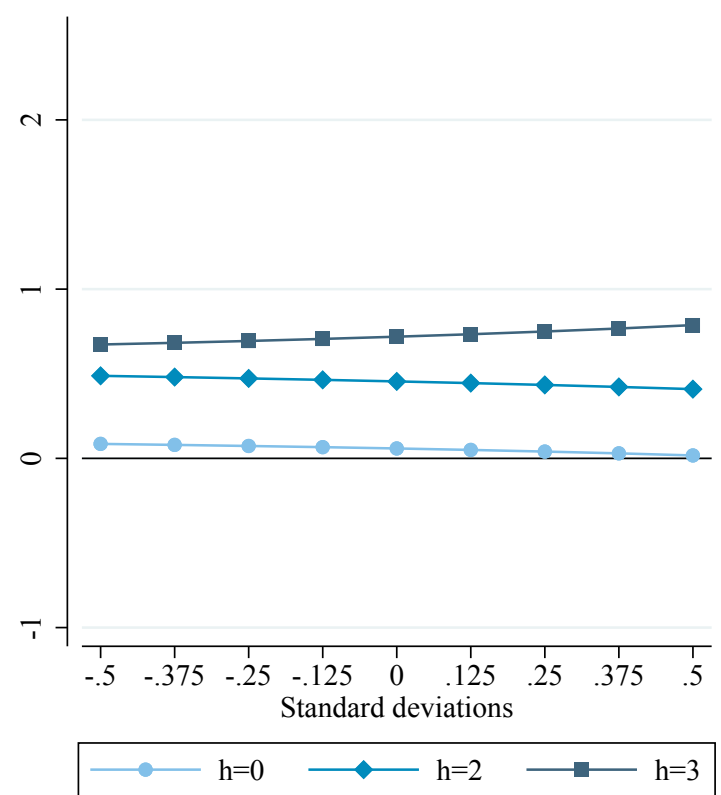

(b) Change in the debt to GDP Ratio

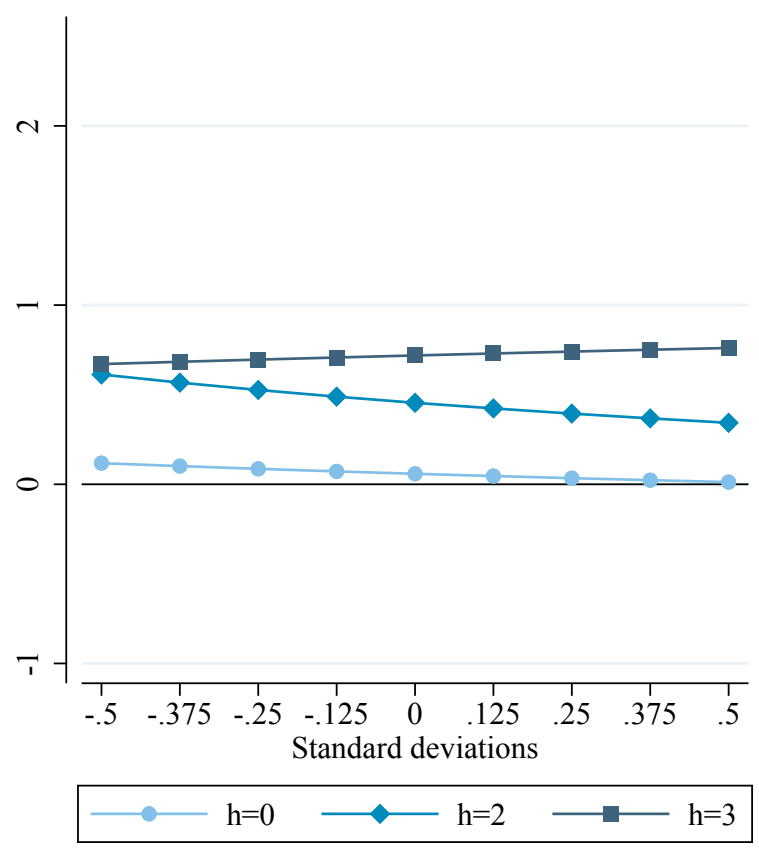

(d) World GDP growth

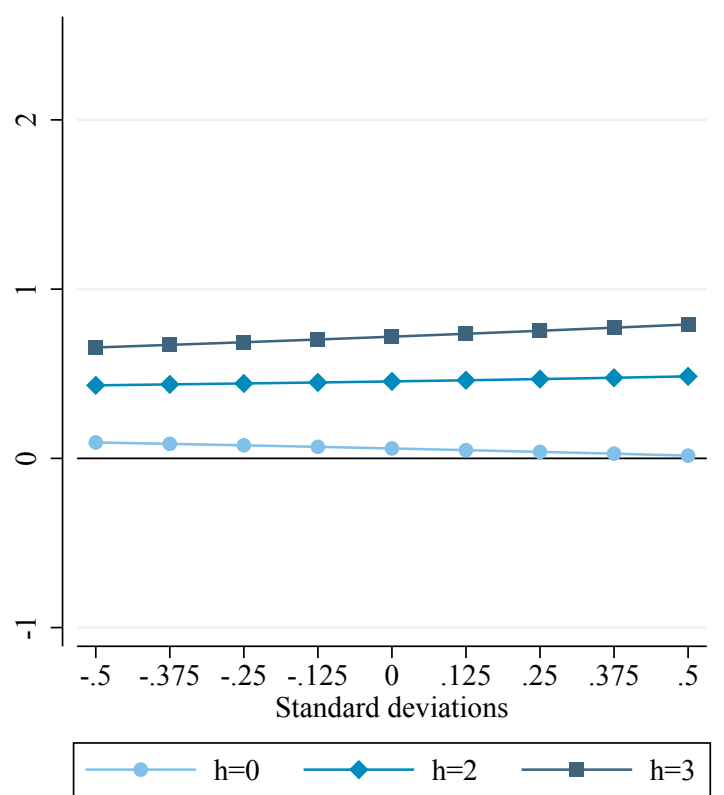

Notes: This chart shows how the cumulative fiscal multiplier varies with the other state variables in our regressions. As before, the multiplier is computed as the cumulative sum of the GDP response relative to the cumulative deficit to GDP response. Each line refers to a different horizon, $h$. As in Figure 2, $h$ goes from the current year $h=0$ to the third year after the shock $h=3 . h=1$ is omitted to avoid overcrowding the figure. Panel (a) shows variation in the multiplier depending on the size of the (lagged) output gap, Panel (b) is for difference changes in the (lagged) deficit to GDP ratio, Panel (c) varies the size of the fiscal consolidation and Panel (d) varies World GDP growth. 
inherent identification issues that researchers face in this area. Our paper tackles a more conceptual problem: there is no such thing as the fiscal multiplier in the data. One of the most obvious reasons is that monetary policy may not offset the effects of fiscal policy in the same way across time or across countries. We show that the Blinder-Oaxaca decomposition provides a natural way to try to disentangle these effects.

Our main result is that fiscal multipliers can be large when monetary policy is less activist. This accords with conventional wisdom and the mechanism can be found in many models. To date, despite the key policy relevance of the issue, empirical evidence on the magnitude of this important interaction remains somewhat limited. In our experiments, fiscal multipliers can be as low zero or as high as 2 and above, depending on the actions of the monetary authority. This has important implications for measuring "the multiplier" and for evaluating and predicting the likely effects of particular macro-policy interventions.

The Blinder-Oaxaca decomposition we propose also has wider implications for measuring the effects of all kinds of policy treatments in macroeconomics, and will allow control for many other possible dimensions of heterogeneity in a very flexible way. Using our decomposition approach, the tasks of estimation and inference can be easily undertaken by using standard linear regression methods while still being sufficiently general to allow for a great deal of unspecified state dependence. We therefore hope these techniques will be of use to all researchers interested in the study of state-dependent, non-linear, and time-varying effects of policy interventions more generally. 


\section{REFERENCES}

Acconcia, Antonio, Giancarlo Corsetti, and Saverio Simonelli. 2014. Mafia and Public Spending: Evidence on the Fiscal Multiplier from a Quasi-experiment. American Economic Review 104(7): 2185-2209.

Angrist, Joshua D., Òscar Jordà, and Guido M. Kuersteiner. 2018. Semiparametric Estimates of Monetary Policy Effects: String Theory Revisited. Journal of Business \& Economic Statistics 36(3): $371-387$.

Auerbach, Alan J., and Yuriy Gorodnichenko. 2012. Measuring the Output Responses to Fiscal Policy. American Economic Journal: Economic Policy 4(2): 1-27.

Bachmann, Rüdiger, and Eric R. Sims. 2012. Confidence and the transmission of government spending shocks. Journal of Monetary Economics 59(3): 235 - 249.

Barro, Robert J., and Charles J. Redlick. 2011. Macroeconomic Effects From Government Purchases and Taxes. Quarterly Journal of Economics 126(1): 51-102.

Blanchard, Olivier, and Roberto Perotti. 2002. An Empirical Characterization of the Dynamic Effects of Changes in Government Spending and Taxes on Output. Quarterly Journal of Economics 117(4): $1329-1368$.

Blinder, Alan S. 1973. Wage Discrimination: Reduced Form and Structural Estimates. Journal of Human Resources 8(4): 436-455.

Born, Benjamin, Falko Juessen, and Gernot J. Müller. 2013. Exchange rate regimes and fiscal multipliers. Journal of Economic Dynamics and Control 37(2): 446-465.

Canova, Fabio, and Evi Pappa. 2011. Fiscal Policy, Pricing Frictions and Monetary Accommodation. Economic Policy 26(1): 555-598.

Chodorow-Reich, Gabriel. 2019. Geographic Cross-Sectional Fiscal Spending Multipliers: What Have We Learned? American Economic Journal: Economic Policy 11(2): 1-34.

Christiano, Lawrence, Martin Eichenbaum, and Sergio Rebelo. 2011. When is the government spending multiplier large? Journal of Political Economy 119(1): 78-121.

Cloyne, James. 2013. Discretionary Tax Changes and the Macroeconomy: New Narrative Evidence from the United Kingdom. American Economic Review 103(4): 1507-1528.

Cloyne, James, Nicholas Dimsdale, and Natacha Postel-Vinay. 2018. Taxes and Growth: New Narrative Evidence from Interwar Britain. NBER Working Paper 24659.

Cloyne, James S., and Paolo Surico. 2017. Household Debt and the Dynamic Effects of Income Tax Changes. Review of Economic Studies 84(1): 45-81.

Corbi, Raphael, Elias Papaioannou, and Paolo Surico. 2019. Regional Transfer Multipliers. Review of Economic Studies 86(5): 1901-1934.

Corsetti, Giancarlo, André Meier, Gernot J. Müller, and Michael B. Devereux. 2012. What determines government spending multipliers? Economic Policy 27(72): 521-565. 
Crafts, Nicholas, and Terence C. Mills. 2013. Rearmament to the Rescue? New Estimates of the Impact of "Keynesian" Policies in 1930s' Britain. Journal of Economic History 73(4): 1077-1104.

DeLong, J Bradford, and Lawrence H Summers. 2012. Fiscal Policy in a Depressed Economy. Brookings Papers on Economic Activity 2012(1): 233-297.

Eggertsson, Gauti B. 2011. What Fiscal Policy is Effective at Zero Interest Rates? In NBER Macroeconomics Annual 2010, edited by Acemoglu, Daron, and Michael Woodford, volume 25, 59-112. Chicago: University of Chicago Press.

Fortin, Nicole, Thomas Lemieux, and Sergio Firpo. 2011. Decomposition Methods in Economics. In Handbook of Labor Economics, edited by Ashenfelter, O., and D. Card, volume 4, chapter 1, 1-102. Amsterdam: Elsevier.

Galí, Jordi. 2015. Monetary Policy, Inflation, and the Business Cycle: An Introduction to the New Keynesian Framework and Its Applications. Princeton, N.J.: Princeton University Press, 2nd edition.

Galí, Jordi, J. David López-Salido, and Javier Vallés. 2007. Understanding the Effects of Government Spending on Consumption. Journal of the European Economic Association 5(1): 227-270.

Guajardo, Jaime, Daniel Leigh, and Andrea Pescatori. 2011. Expansionary Austerity: New International Evidence. IMF Working Paper WP/11/158.

Guajardo, Jaime, Daniel Leigh, and Andrea Pescatori. 2014. Expansionary Austerity? International Evidence. Journal of the European Economic Association 12(4): 949-968.

Gunter, Samara, Daniel Riera-Crichton, Carlos Végh, and Guillermo Vuletin. 2018. Non-Linear Effects of Tax Changes on Output: The Role of the Initial Level of Taxation. World Bank Policy Research Working Paper 8668.

Guren, Adam M., Alisdair McKay, Emi Nakamura, and Jón Steinsson. 2020. Housing Wealth Effects: The Long View. Review of Economic Studies Forthcoming.

Hamilton, James D. 1994. Time Series Analysis. Princeton, N.J.: Princeton University Press.

Hayo, Bernd, and Matthias Uhl. 2014. The Macroeconomic Effects of Legislated Tax Changes in Germany. Oxford Economic Papers 66(2): 397-418.

Hussain, Syed M., and Liu Lin. 2018. Comparing the Effects of Discretionary Tax Changes between the US and the UK. The B.E. Journal of Macroeconomics 18(1): 1-17.

Ilzetzki, Ethan, Enrique G. Mendoza, and Carlos A. Végh. 2013. How big (small?) are fiscal multipliers? Journal of Monetary Economics 6o(2): 239-254.

Jordà, Òscar. 2005. Estimation and Inference of Impulse Responses by Local Projections. American Economic Review 95(1): 161-182.

Jordà, Òscar, Moritz Schularick, and Alan M. Taylor. 2017. Macrofinancial History and the New Business Cycle Facts. NBER Macroeconomics Annual 31(1): 213-263.

Jordà, Òscar, Moritz Schularick, and Alan M. Taylor. 2020. The effects of quasi-random monetary experiments. Journal of Monetary Economics 112: 22-40. 
Jordà, Òscar, and Alan M. Taylor. 2016. The Time for Austerity: Estimating the Average Treatment Effect of Fiscal Policy. Economic Journal 126(590): 219-255.

Kato, Akihisa, Wataru Miyamoto, Thuy Lan Nguyen, and Dmitriy Sergeyev. 2018. The Effects of Tax Changes at the Zero Lower Bound: Evidence from Japan. AEA Papers and Proceedings 108: 513-18.

Keynes, John Maynard. 1936. The Marginal Propensity to Consume and the Multiplier. In The General Theory of Employment, Interest, and Money, chapter 10. London: Macmillan.

Leeper, Eric M., Michael Plante, and Nora Traum. 2010. Dynamics of fiscal financing in the United States. Journal of Econometrics 156(2): 304-321.

Leeper, Eric M, Nora Traum, and Todd B. Walker. 2017. Clearing Up the Fiscal Multiplier Morass. American Economic Review 107(8): 2409-54.

Mertens, Karel, and Morten O. Ravn. 2013. The Dynamic Effects of Personal and Corporate Income Tax Changes in the United States. American Economic Review 103(4): 1212-1247.

Miyamoto, Wataru, Thuy Lan Nguyen, and Dmitriy Sergeyev. 2018. Government Spending Multipliers under the Zero Lower Bound: Evidence from Japan. American Economic Journal: Macroeconomics 10(3): $247-77$.

Mountford, Andrew, and Harald Uhlig. 2009. What are the Effects of Fiscal Policy Shocks. Journal of Applied Econometrics 24(6): 960-992.

Nakamura, Emi, and Jón Steinsson. 2014. Fiscal Stimulus in a Monetary Union: Evidence from US Regions. American Economic Review 104(3): 753-92.

Nguyen, Anh D. M., Luisanna Onnis, and Raffaele Rossi. 2020. The Macroeconomic Effects of Income and Consumption Tax Changes. American Economic Journal: Economic Policy. Forthcoming.

Oaxaca, Ronald. 1973. Male-Female Wage Differentials in Urban Labor Markets. International Economic Review 14(3): 693-709.

Ramey, Valerie A. 2016. Macroeconomic Shocks and Their Propagation. In Handbook of Macroeconomics, edited by Taylor, John B., and Harald Uhlig, volume 2, chapter 2, 71-162. Amsterdam: Elsevier.

Ramey, Valerie A., and Sarah Zubairy. 2018. Government Spending Multipliers in Good Times and in Bad: Evidence from US Historical Data. Journal of Political Economy 126(2): 850-901.

Riera-Crichton, Daniel, Carlos A. Vegh, and Guillermo Vuletin. 2015. Procyclical and countercyclical fiscal multipliers: Evidence from OECD countries. Journal of International Money and Finance 52: 15-31.

Romer, Christina D., and David H. Romer. 2010. The Macroeconomic Effects of Tax Changes: Estimates Based on a New Measure of Fiscal Shocks. American Economic Review 100(3): 763-801.

Rubin, Donald B. 1974. Estimating Causal Effects of Treatments in Randomized and Nonrandomized Studies. Journal of Educational Psychology 66(5): 688-701.

Tenreyro, Silvana, and Gregory Thwaites. 2016. Pushing on a String: US Monetary Policy Is Less Powerful in Recessions. American Economic Journal: Macroeconomics 8(4): 43-74. 
Uhlig, Harald. 2010. Some Fiscal Calculus. American Economic Review 100(2): 30-34.

Woodford, Michael. 2011. Simple Analytics of the Government Expenditure Multiplier. American Economic Journal: Macroeconomics 3(1): 1-35.

Wooldridge, Jeffrey M. 2001. Econometric Analysis of Cross Section and Panel Data. Cambridge, Mass.: MIT Press. 


\section{ONLINE APPENDIX}

\section{A: Original Guajardo, Leigh, and Pescatori (2014) specification}

Figure A.1: Effects of a $1 \%$ of GDP fiscal consolidation: original IMF specification

(a) \% response of GDP

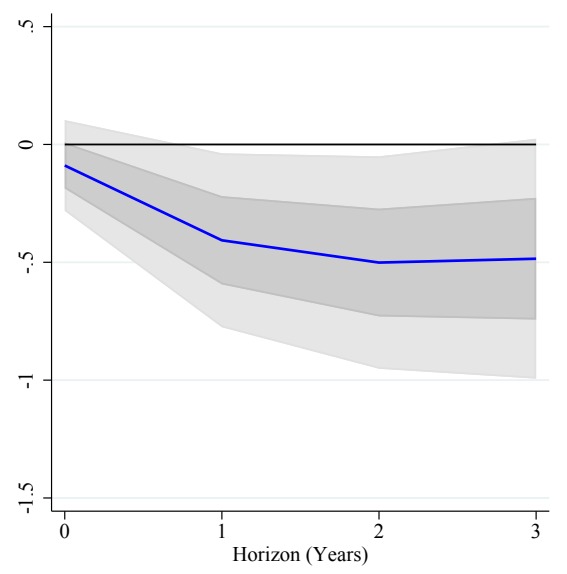

(b) Response of the short term real interest rate

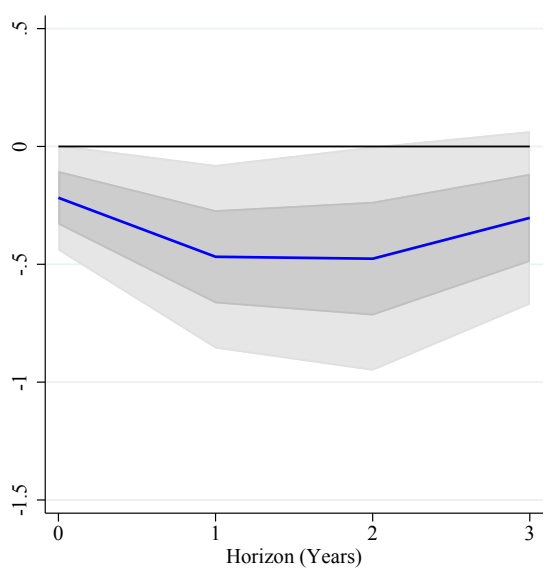

Notes: Vertical axes reported in percent change with respect to the origin. One and two standard deviation confidence bands for each coefficient estimate shown as grey areas. Local projections as specified in equation (1) using two lags of each control described therein. Sample 1978:1-2009:4. This specification uses the original control set from Guajardo, Leigh, and Pescatori (2014). See text for details. 


\section{B. VARIATION IN THE DEFICIT TO GDP RATIO BY MONETARY POLICY RESPONSE}

Figure A.2: Deficit/GDP ratio $\left(\left(D_{t+h}-D_{t-1}\right) / Y_{t-1}\right)$

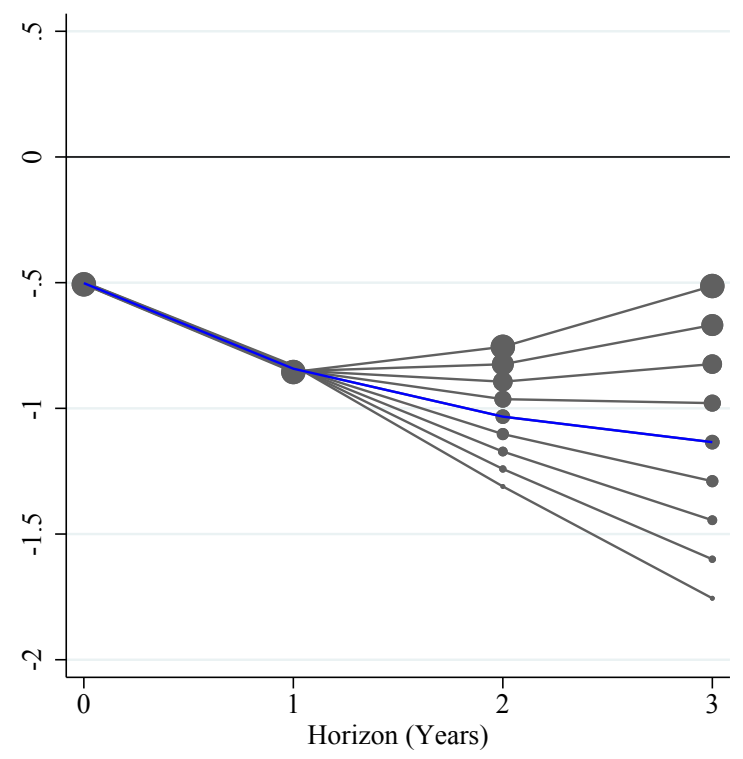

Notes: This Figure shows how the response of the deficit to GDP ratio varies with the degree of monetary policy accommodation. The blue lines report the direct effect. The gray lines consider experiments which vary the degree of monetary accommodation. A larger marker indicates a tighter monetary policy scenario. 


\section{SignificANCE OF THE DIRECT EFFECT}

Figure A.3: Direct effect: response of GDP (\%) to a $1 \%$ of GDP fiscal consolidation

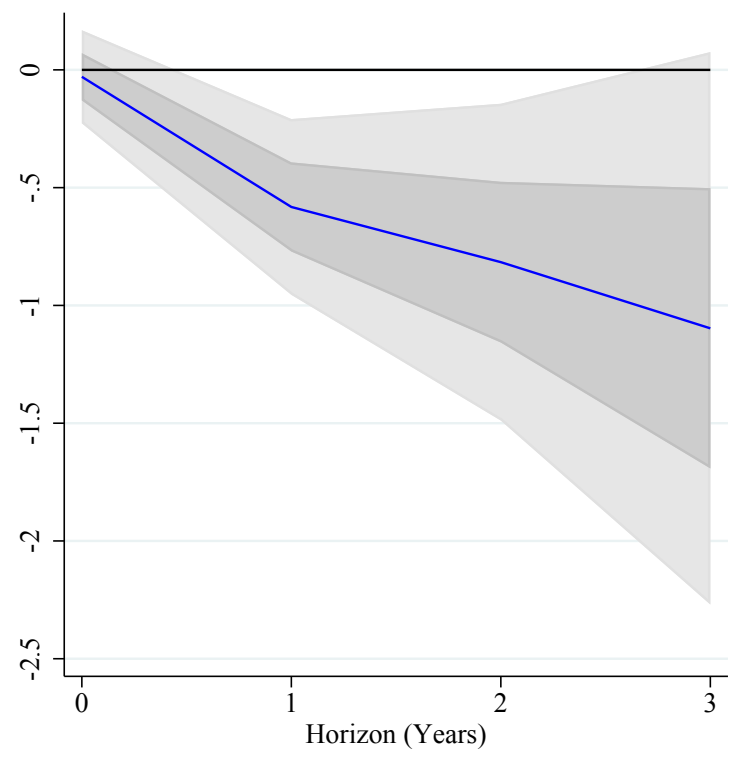

Notes: This Figure shows how the response GDP (\%) following a 1\% of GDP fiscal consolidation. The blue lines report the direct effect estimated from the Blinder-Oaxaca decomposition together with the one and two standard deviation error bands. 


\section{Coefficient estimates}

Table A.1: Coefficient estimates for the direct and indirect effects

\begin{tabular}{ccc}
\hline Horizon (Years) & $\beta^{h}$ & $\theta_{f}^{h}$ \\
\hline 0 & -0.03 & -0.50 \\
& $(0.10)$ & $(0.43)$ \\
1 & -0.58 & -0.60 \\
& $(0.19)$ & $(0.29)$ \\
2 & -0.82 & -0.71 \\
& $(0.34)$ & $(0.15)$ \\
3 & -1.10 & -1.25 \\
& $(0.60)$ & $(0.16)$ \\
\hline
\end{tabular}

Notes: This table reports coefficient estimates based on equation $15 . \quad \beta^{h}$ is the impulse response function for the direct effect and therefore corresponds to the Figure A.3. $\theta_{f}^{h}$ governs the strength of the indirect effect. A negative value implies that, following a fiscal consolidation, real GDP is more negative when monetary policy is less accommodative. Standard errors are reported in parenthesis. 


\section{E. RESPONSE OF THE REAL RATE}

Figure A.4: Response of the real interest rate by monetary regime

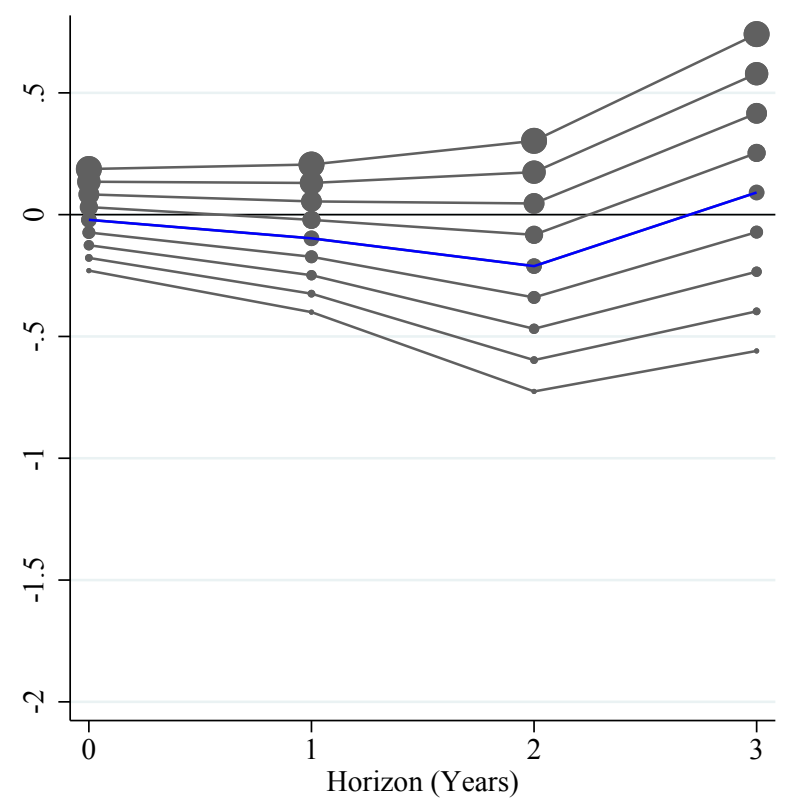

Notes: This Figure shows the response of the real interest rate to a $1 \%$ of GDP fiscal consolidation. The blue lines report the direct effect. The gray lines consider experiments which vary the degree of monetary accommodation. A larger marker indicates a tighter monetary policy scenario. 


\section{F: Alternative PRoxy fOR the MONETARy REgIME}

Figure A.5: Theoretical state dependence versus Blinder-Oaxaca estimates

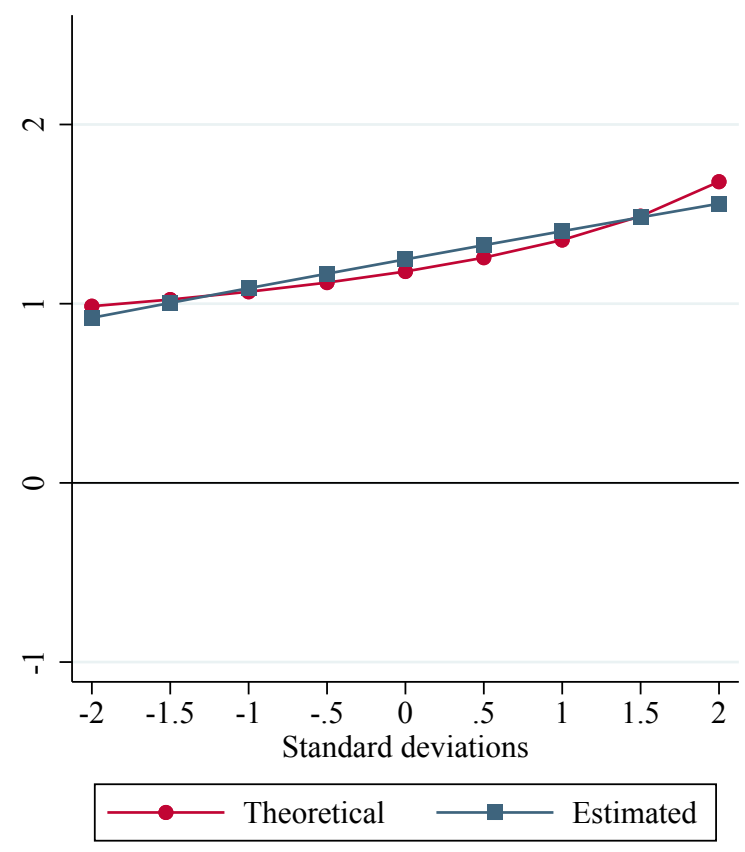

Notes: This chart shows how the peak cumulative fiscal multiplier varies with the monetary policy response both in theory and when the effect is estimated on simulated data. The red circles show the true theoretical variation in the simulated dataset. The blue squares show the empirical estimates obtained by using our Blinder-Oaxaca decomposition estimated on data simulated from the model. This figure is produced using an extended version of the model where the multiplier also varies with the share of hand to mouth households. The monetary regime is then estimates from a Taylor Rule regression. See main text for details. 
Figure A.6: Cumulative fiscal multiplier by monetary response

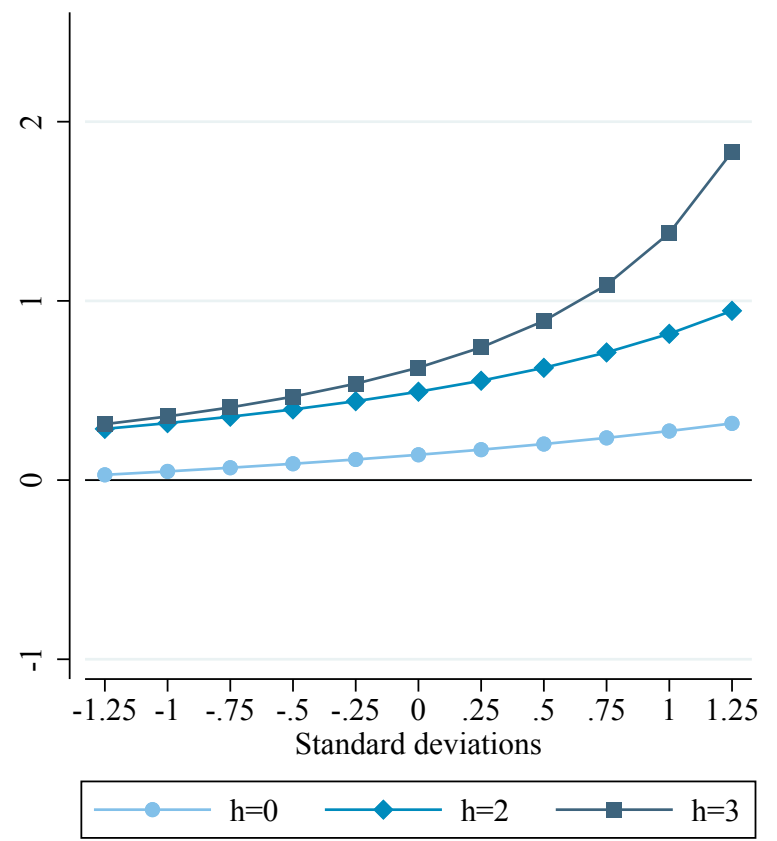

Notes: This chart shows the cumulative fiscal multiplier varying the degree of monetary offset. This is computed as the cumulative sum of the GDP response relative to the cumulative deficit to GDP response. Each line refers to a different horizon, $h$. As in Figure 2, $h$ goes from the current year $h=0$ to the third year after the shock $h=3 . h=1$ is omitted to avoid overcrowding the figure. Relative to the baseline figure in the main text, this is produced using the alternative monetary regime proxy as discussed in Section 6 . Note that the standard deviation of the two proxies (the new proxy and the baseline method) are different. The experiment here is therefore calibrated so the real interest rate varies on impact by a similar amount to the baseline figure. 


\section{G. CONTROLLING FOR FISCAL COMPOSITION}

Figure A.7: Cumulative fiscal multiplier by monetary response

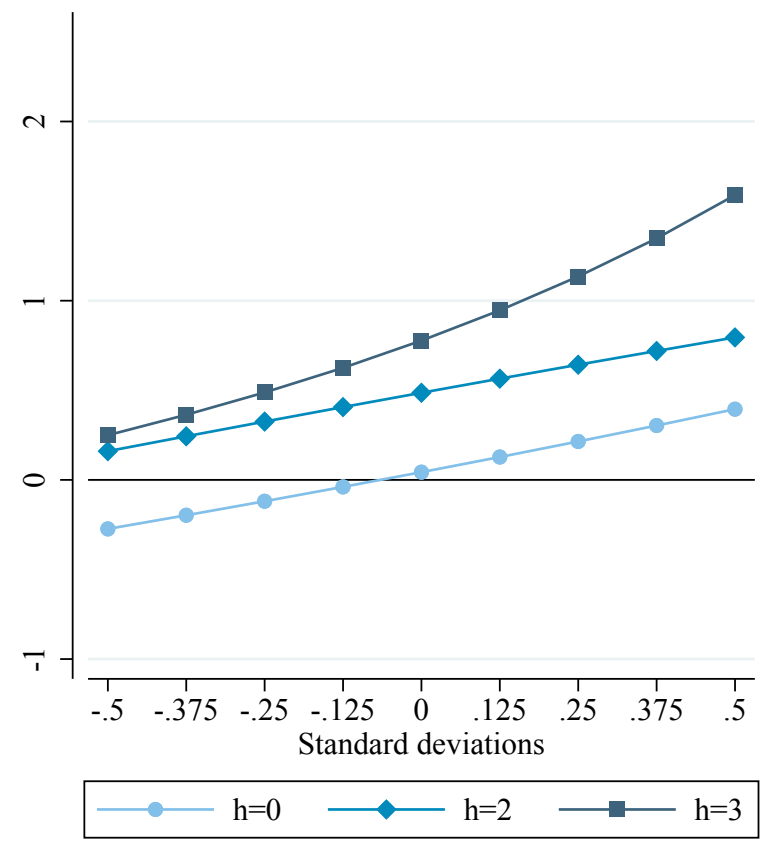

Notes: This chart shows the cumulative fiscal multiplier varying the degree of monetary offset. This is computed as the cumulative sum of the GDP response relative to the cumulative deficit to GDP response. Each line refers to a different horizon, $h$. As in Figure $2, h$ goes from the current year $h=0$ to the third year after the shock $h=3 . h=1$ is omitted to avoid overcrowding the figure. Relative to the baseline figure in the main text, this is produced controlling for the cross-country propensity to use taxes versus spending instruments, as discussed in Section 6. 


\section{H. Robustness EXERCISES: DEFICIT/GDP RATIO}

Figure A.8: Robustness exercises: deficit/GDP ratio $\left(\left(D_{t+h}-D_{t-1}\right) / Y_{t-1}\right)$

(a) Time fixed effects

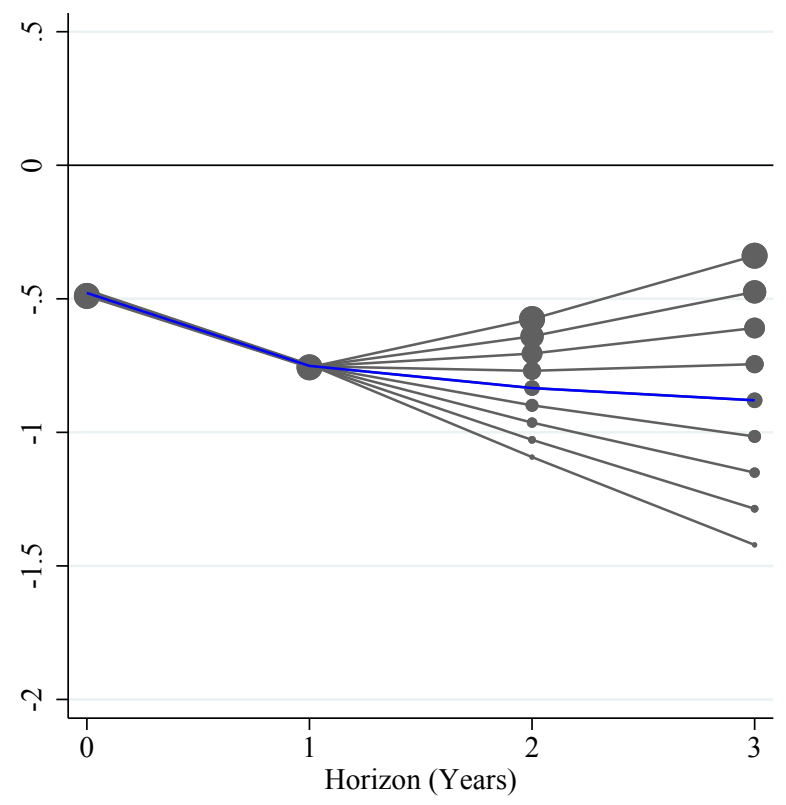

(c) Alternative interactions approach

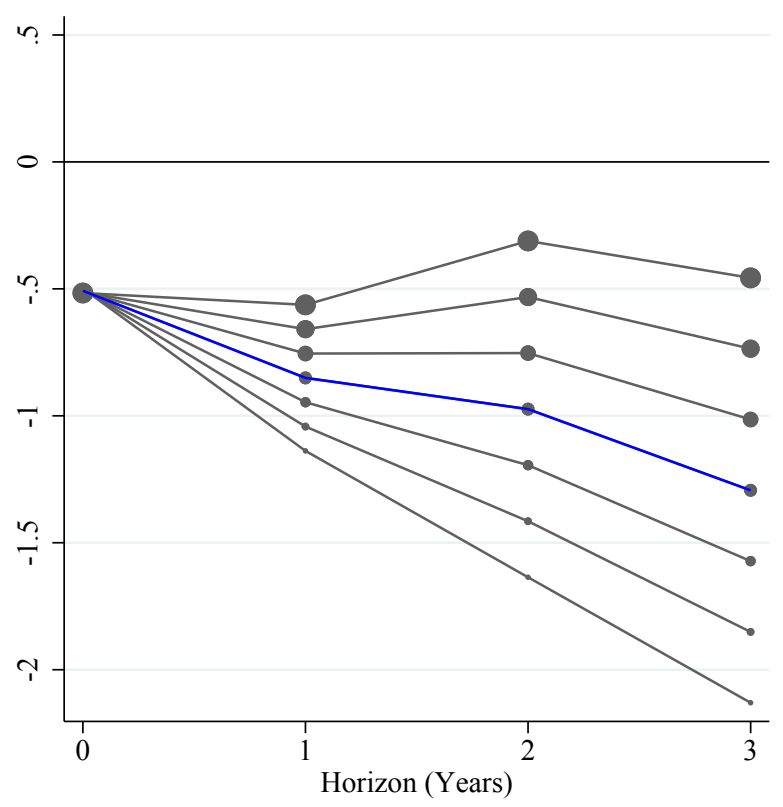

(b) Longer lag structure

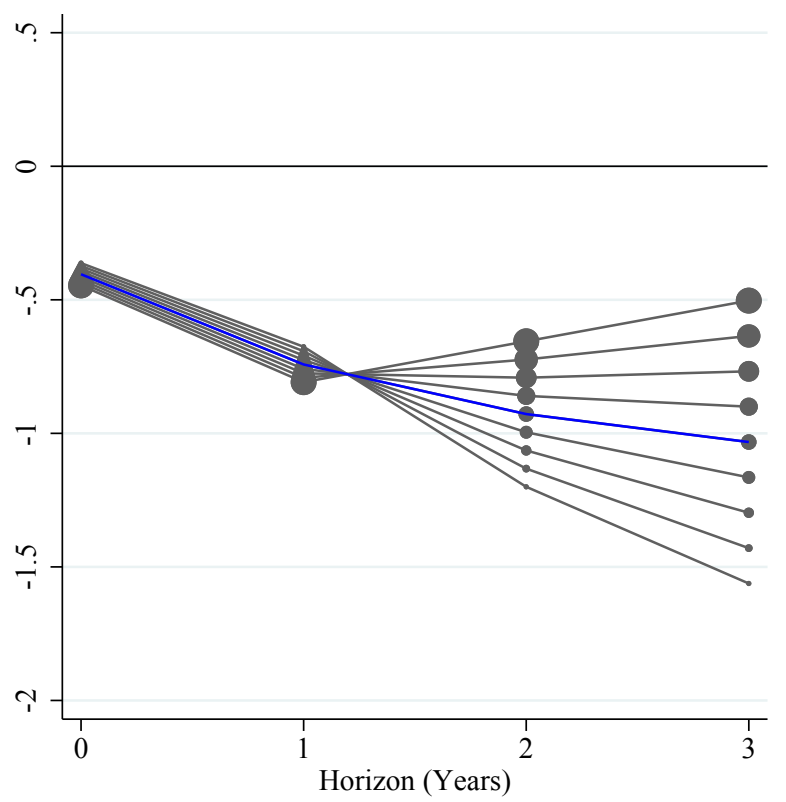




\section{I: FURTHER DETAILS ON THE MODEL}

The model is a simple variant of the textbook 3-equation New Keynesian model (e.g., as in Gal'1, 2015) with optimizing and hand-to-mouth households as in Gal'1, López-Salido, and Vallés (2007). The details below are therefore very standard.

\section{Households}

Savers The economy is populated by $1-\mu$ saver/optimizing households:

$$
\max _{C_{t}, N_{t}, B_{t}} E_{\mathrm{O}} \sum_{t=\mathrm{o}}^{\infty} \beta^{t}\left(\log C_{t}-\frac{N_{t}^{1+\psi}}{1+\psi}\right),
$$

subject to

$$
P_{t} C_{t}+Q_{t} B_{t}=B_{t-1}+W_{t} N_{t}+D_{t}-T_{t}
$$

Which leads to the following set of first order conditions:

$$
\begin{gathered}
\left(C_{t}\right): \lambda_{t}=C_{t}^{-\sigma}, \\
\left(N_{t}\right): \lambda_{t} \frac{W_{t}}{P_{t}}=N_{t}^{\psi}, \\
\left(B_{t}\right): Q_{t}=1 / R_{t}=1 /\left(1+i_{t}\right)=\beta E_{t} \frac{\lambda_{t+1}}{\lambda_{t}} \frac{P_{t}}{P_{t+1}},
\end{gathered}
$$

where saver households own firms and receive any profits $D_{t}$ lump sum. These households also finance government activities via a lump sum tax $T_{t}$.

In linearized form these equilibrium conditions can be written as:

$$
\begin{gathered}
\hat{w}_{t}=\hat{c}_{t}^{S}+\psi \hat{n}_{t}^{S}, \\
E_{t} \Delta \hat{c}_{t+1}^{S}=\frac{1}{\sigma}\left(\hat{i}_{t}-E_{t} \hat{\pi}_{t+1}\right) .
\end{gathered}
$$

Non-savers Non-saver rule of thumb households simply consume their entire labor income.

$$
C_{t}^{N}=w_{t} N_{t}^{N}
$$

They also, in principle, have an intratemporal labor supply condition which comes from solving the same optimization problem as above for $C$ and $N$ but where $B=D=T=0$.

$$
\frac{W_{t}}{P_{t}}=C_{t}^{N} N_{t}^{N^{\psi}}
$$

Total consumption is given by:

$$
C_{t}=\mu C_{t}^{N}+(1-\mu) C_{t}^{S} .
$$

In linearized form these are: 


$$
\begin{gathered}
\hat{w}_{t}=\hat{c}_{t}^{N}+\psi \hat{n}_{t}^{N}, \\
\hat{c}_{t}^{N}=\hat{w}_{t}+\hat{n}_{t}^{N}, \\
\hat{c}_{t}=\mu \frac{C^{N}}{C} \hat{c}_{t}^{N}+(1-\mu) \frac{C^{S}}{C} \hat{c}_{t}^{S} .
\end{gathered}
$$

\section{Firms}

Final goods firms Different varieties of goods $y(j)_{t}$ are aggregated by the final goods firm:

$$
Y_{t}=\left[\int_{0}^{1} y_{t}(j)^{\frac{\epsilon-1}{\epsilon}} d j\right]^{\frac{\epsilon}{(\epsilon-1)}}
$$

where $\epsilon$ is price elasticity of demand for good $j$. Final goods firms choose intermediate inputs to maximize profit:

$$
\max _{y_{t}(j)}\left(P_{t}\left[\int_{0}^{1} y_{t}(j)^{\frac{\epsilon-1}{\epsilon}} d j\right]^{\frac{\epsilon}{(\epsilon-1)}}-\int_{0}^{1} p_{t}(j) y_{t}(j) d j\right) .
$$

Which yields the following demand curve and aggregate price index

$$
\begin{gathered}
y_{t}(j)=\left(\frac{p_{t}(j)}{P_{t}}\right)^{-\epsilon} Y_{t}, \\
P_{t}=\left(\int_{0}^{1} p_{t}(j)^{1-\epsilon} d j\right)^{\frac{1}{1-\epsilon}} .
\end{gathered}
$$

Intermediate goods firms Intermediate goods firms solve a static labor demand problem and an intertemporal pricing problem subject to Calvo pricing frictions. Each period firms can re-optimize labor demand.

The firm minimizes labor costs by choosing $n(j)_{t}$ to minimize the following Lagrangian:

$$
\min _{n_{t}(j)} \frac{W_{t}}{P_{t}} n_{t}(j)+m c_{t}\left(y_{t}(j)-A n_{t}(j)\right)
$$

where $m c_{t}$ is real marginal cost. The first order condition is:

$$
m c_{t}=\left(W_{t} / P_{t}\right) / A
$$

When the firm is able to re optimize, they choose $p_{t}(j)$ to maximize expected profits:

$$
E_{t} \sum_{s=0}^{\infty} \theta^{s}\left(\beta^{s} \frac{\lambda_{t+s}}{\lambda_{t}}\right)\left[\frac{p_{t}(j)}{P_{t+s}} y_{t+s}(j)-m c_{t+s} y_{t+s}(j)\right],
$$

subject to

$$
y_{t}(j)=\left(\frac{p_{t}(j)}{P_{t}}\right)^{-\epsilon} Y_{t}
$$


which yields:

$$
\sum_{s=0}^{\infty} \theta^{s} E_{t}\left(\beta^{s} \frac{\lambda_{t+s}}{\lambda_{t}}\right)\left(\frac{p_{t}^{*}}{P_{t+s}} y_{t+s}(j)-\frac{\epsilon}{\epsilon-1} m c_{t+s} y_{t+s}(j)\right)=0 .
$$

Linearization of equation 38 and the price index 31 yields the New Keynesian Phillips Curve given in the text.

\section{Policy}

As mentioned in the main text, government consumption is simply a persistent exogenous stream of purchases funded with lump sum taxes on savers. The budget constraint is therefore:

$$
G_{t}=T_{t} .
$$

In linearized form, government spending evolves as follows:

$$
\hat{g}_{t}=\rho_{g} \hat{g}_{t-1}+e_{t}
$$

where $e_{t}$ is a mean zero i.i.d. shock.

Monetary policy follows a simple Taylor Rule. The nominal interest rate $\hat{i}_{t}$, written in deviations from steady state, is set relative to inflation. Importantly, we will think of this rule as varying across country, $c$, but where each country operates as a closed economy. The policy rule is therefore:

$$
\hat{i}_{t}=\rho_{i} \hat{i}_{t-1}+\left(1-\rho_{i}\right) \phi^{c} \hat{\pi}_{t},
$$

